\title{
Hsp90 inhibitor as a sensitizer of cancer cells to different therapies (Review)
}

\author{
ZUZANA SOLÁROVÁ ${ }^{1}$, JÁN MOJŽIŠ ${ }^{1}$ and PETER SOLÁR ${ }^{2}$ \\ ${ }^{1}$ Department of Pharmacology, Faculty of Medicine, ${ }^{2}$ Laboratory of Cell Biology, Institute of Biology \\ and Ecology, Faculty of Science, P.J. Šafárik University, 04001 Košice, Slovak Republic
}

Received September 10, 2014; Accepted October 22, 2014

DOI: 10.3892/ijo.2014.2791

\begin{abstract}
Hsp90 is a molecular chaperone that maintains the structural and functional integrity of various client proteins involved in signaling and many other functions of cancer cells. The natural inhibitors, ansamycins influence the Hsp90 chaperone function by preventing its binding to client proteins and resulting in their proteasomal degradation. $\mathrm{N}$ and C-terminal inhibitors of $\mathrm{Hsp} 90$ and their analogues are widely tested as potential anticancer agents in vitro, in vivo as well as in clinical trials. It seems that Hsp90 competitive inhibitors target different tumor types at nanomolar concentrations and might have therapeutic benefit. On the contrary, some Hsp90 inhibitors increased toxicity and resistance of cancer cells induced by heat shock response, and through the interaction of survival signals, that occured as side effects of treatments, could be very effectively limited via combination of therapies. The aim of our review was to collect the data from experimental and clinical trials where Hsp90 inhibitor was combined with other therapies in order to prevent resistance as well as to potentiate the cytotoxic and/or antiproliferative effects.
\end{abstract}

\section{Contents}

1. Introduction

2. Hsp90 inhibitors - potential therapeutic agents

3. Inhibitors of the N-teminal ATP binding pocket

4. Inhibitors of the C-terminal ATP binding pocket

5. Combination of Hsp90 inhibitor with second therapy

6. Resistance to Hsp90 inhibitors

7. Combination of Hsp inhibitors

Correspondence to: Dr Peter Solár, Laboratory of Cell Biology, Institute of Biology and Ecology, Faculty of Science, P.J. Šafárik University, 04001 Košice, Slovak Republic

E-mail: peter.solar@upjs.sk

Key words: Hsp90, chaperone, Hsp90 inhibitor, cancer, resistance

\section{Introduction}

The cell responds to environmental stress by increasing synthesis of several molecular chaperons known as heat shock proteins (Hsp). These proteins are cathegorized according to their molecular weight into five classes: small Hsp, Hsp60, Hsp70, Hsp90 and Hsp100. One of the most abundant molecular chaperones is Hsp90, which is a highly conserved protein, whose association is required for the stability and function of multiple-mutated, chimeric- and overexpressedsignaling proteins that promote the growth and/or survival of cancer cells (1). Hsp90 client proteins lack specific Hsp90 binding motifs and vary in terms of intracellular localization, structure, and function. Their main common denominator is their role in promoting cell proliferation and protection from apoptosis (2). Hsp90 is involved in the maturation and stabilization of a wide range of oncogenic client proteins which are crucial for oncogenesis and malignant progression (3), such as signal transduction molecules (Src, Raf1 and cdk4) and steroid receptors and in enhancing the activity of telomerase and nitric-oxide synthase (4). For the updated list of Hsp90 client proteins see http://www.picard.ch/download. Under normal growth conditions, Hsp90 plays a major role in various aspects of the secretory pathway, cellular transport and during environmental stress. Hsp90 is required for the cell cycle, meiosis and cytokinesis (5), however, Hsp90 does not participate in general protein folding (6). Recent studies also indicate that many types of cells express Hsp90 on the cell surface and secrete Hsp90 into the extracellular space to carry out important extracellular functions (7).

\section{Hsp90 inhibitors - potential therapeutic agents}

There are several reasons why Hsp90 should be considered an important target for cancer therapy. One is that Hsp90 protein is involved in the maturation and stabilization of a wide range of oncogenic proteins (Bcr-Abl, HER-2, EGFR, C-Raf, B-Raf, Akt, Met, VEGFR, FLT3, AR and ER, HIF-1 $\alpha$ ) and telomerase (8), which are included in tumor formation and therefore causing certain dependence of cancer cells on Hsp90 function. Secondly, unsuitable environmental conditions in cancer cells (hypoxia, low $\mathrm{pH}$, poor nutritional conditions) may result in the destabilization of proteins, and therefore the function of Hsp90 for such cells is necessary. In 
addition, Hsp90 protein exists as a multi-chaperone complex with unusually high affinity for ATP and some substances in tumor cells (8), whereas in normal cells a latent form of Hsp90 protein is present. In this regard, Hsp90 protein of tumor cells has higher affinity for inhibitors (9), caused by a change in binding of ATP to Hsp90 as an effect of co-chaperones, that modulate the function of Hsp90, as well as by higher ATPase activity of Hsp90 protein, whereas in normal cells Hsp90 is found mostly in a latent or inactive form (10). Furthermore, Hsp90 is constitutively, and 2-10 times more expressed in tumor cells than in normal ones, which means, that the correct function of $\mathrm{Hsp} 90$ is essential for the growth and survival of tumor cells (11). Hsp90 inhibition may lead to the degradation of proteins involved in the so-called six main characteristics of cancer: i) the ability to produce growth factors, ii) resistance to anticancer agents, iii) avoidance of apoptosis, iv) unlimited replicative potential, v) uninterrupted angiogenesis and vi) invasiveness and metastasis $(8,12,13)$.

The Hsp90 monomer is composed of four domains: a highly conserved $\mathrm{N}$ - and $\mathrm{C}$-terminal domain, a middle domain and a charged linker region that connects to both $\mathrm{N}$-terminal as well as middle domain (14). A long, highly charged linker between the $\mathrm{N}$-terminal domain and the middle domain is a special characteristic of Hsp90s in eukaryotic organisms (15). $\mathrm{N}$-terminal domain contains ATP-binding site, thus blocking of ATP binding can serve as a single well known mechanism of Hsp90 inhibitors. Middle domain is responsible for co-chaperone and clients binding and its function is probably discrimination between various types of client proteins during their processes of activation (16). C-terminal domain is used for dimerization of Hsp90 and it is supposed, that it contains a second nucleotide-binding site, which has been shown to bind to novobiocin, epigallocatechin (ECGC) and taxol. However, neither the apo-form crystal structure, nor any complex structure verified this prediction (17).

\section{Inhibitors of the N-teminal ATP binding pocket}

Hsp90 inhibitors are divided into several groups according to the form of inhibition, which includes: i) blocking the binding of ATP, ii) decoupling co-chaperon/Hsp90 and iii) antagonism of client/Hsp90 association. The benzoquinone ansamycins mimic ATP and bind to the nucleotide-binding pocket on the $\mathrm{N}$-terminus of Hsp90, blocking the natural substrate ATP binding (18). Geldanamycin (GA) and its analogs specifically inhibit only Hsp90 (and its endoplasmic reticulum homolog grp94), but not other chaperones or other intracellular molecular targets (19). Hsp90 inhibitor 17-allylamino-17-demethoxygeldanamycin (17-AAG) administration was shown to induce a pronounced downregulation of multiple Hsp90 protein clients and other downstream effectors, such as IGF-IR, Akt, IKK- $\alpha$, IKK- $\beta$, FOXO1, Erk1/2 and c-Met, resulting in sequestration-mediated inactivation of $\mathrm{NF}-\mathrm{\kappa B}$, reduced cell proliferation and decline of cell motility (20). The inhibition of Hsp90 with 17-AAG and another ansamycin derivative 17-(dimethylaminoethylamino)-17-demethoxygeldanamycin (17-DMAG) downregulated B-Raf, decreased cell proliferation, reduced Mek/Erk signaling activation and induced a significant inhibition of telomerase activity in melanoma cells $(21,22)$. On the contrary, treatment with 17-AAG triggers a stress response in cells that leads to activation of the transcription factor of Hsp-1 (HSF-1), resulting in elevation of anti-apoptotic Hsp90, Hsp70, and Hsp27 chaperons (23).

Although GA exhibits very strongly in vitro antitumor activities, its clinical potential is unfortunately low, due to poor solubility in aqueous solutions and its hepatotoxicity (24). Therefore, GA derivatives with comparable antitumor effects and even better toxicological properties have been synthesized. Following derivatives of GA have entered into the clinical trials (per August 2014): 17-AAG (tanespimycin; CNF1010 - an oil-in-water nanoemulsion of 17-AAG; 39 trials), 17-DMAG (alvespimycin; 7 trials), IPI-504 (retaspimycin hydrochloride; 13 trials) and most recently 17-amino-17-demethoxygeldanamycin (17-AG or IPI-493; 2 trials). 17-AAG is one of the derivatives which has entered to the third phase of the clinical trials. Furthermore, there are phenol derivatives produced by Kosan and Biotica, which demonstrated cell growth inhibition comparable to 17-AAG and 17-DMAG (25). These compounds are in preclinical stages of development.

Another intensively studied N-terminal domain binder of Hsp90 is radicicol, a macrocyclic natural antibiotic isolated from the fungus Monocillium nordinii and from the plantassociated fungus Chaetomium chiversii (26). Despite the potent antitumoral activity in vitro, radicicol has little or no activity in vivo $(27,28)$. On the contrary, newly created stable oxime derivatives of radicicol and cykloproparadicicol have shown antitumor activity with tolerable toxicity in animal models (28). Moreover, synthetic Hsp90 inhibitors with resorcinol moiety NVP-AUY922 (27 trials) and AT-13387 (6 trials) are now in phase I-II and phase I clinical trials, respectively.

With the aim to improve pharmacological properties and even increase the specificity of Hsp90 inhibitors, many phamacological companies focused on the synthesis of small molecules. Chiosis et al (29) demonstrated the effect of the first identified purine scaffold inhibitor PU3 comparable to GA in breast cancer cells. Kasibhatla et al (30) modified such a purine inhibitor by rotating the $\mathrm{C} 8$-attached aryl ring to the $\mathrm{N} 9$ position. This resulted in the compound CNF2024/BIIB021 identified as a stronger inhibitor compared to $17-\mathrm{AAG}$ in vitro and in vivo (31), which is currently involved in phase II clinical trials ( 7 trials). Interestingly, purine-scaffold inhibitors have better solubility in aqueous solutions, metabolic stability and can be administered orally compared to ansamycin Hsp90 inhibitors (32). PU-H71 derivative is now in phase I clinical trials (2 trials).

Using a chemical proteomics approach, Serenex company identified small molecules, that are distinct from GA (structures not disclosed). Water soluble and orally active compound SNX-5422, administered in xenograft models, resulted in partial tumor regression (33) and is currently involved in phase I clinical trials (10 trials).

Synta Pharmaceuticals Corporation developed another second-generation Hsp90 inhibitor ganetespib (formerly STA-9090), a unique resorcinolic triazolone (chemical structure distinct from 17-AAG), undergoing now phases II-III clinical trials (32 trials).

Couple of additional Hsp90 inhibitors have been described and entered phase I-II of clinical trials. Details as follows: KW-2478 (2 trials), Hsp990 (2 trials), MPC-3100 (1 trial), 
Table I. Published phase II study results of Hsp90 inhibitors.

\begin{tabular}{|c|c|c|}
\hline Hsp90 inhibitor & Responses of cancer patients & Authors (Ref.) \\
\hline 17-AAG & $\begin{array}{l}\text { No objective response in the treatment of clear cell or } \\
\text { papillary renal cell carcinoma }\end{array}$ & Ronnen et al, 2006 (163) \\
\hline $17-\mathrm{AAG}$ & No activity with regard to prostate-specific antigen response & Heath et al, 2008 (164) \\
\hline 17-AAG & No objective antimelanoma responses & Solit et al, 2008 (90) \\
\hline IPI-504 & $\begin{array}{l}\text { Activity in NSCLS patients, particularly among those with ALK } \\
\text { rearrangements }\end{array}$ & Sequist et al, 2010 (165) \\
\hline IPI-504 & Not warranted in patients with castration-resistant prostate cancer & Oh et al, 2011 (166) \\
\hline 17-AAG + bortezomib & $\begin{array}{l}\text { Significant and durable responses with acceptable toxicity } \\
\text { (relapsed or relapsed and refractory multiple myeloma) }\end{array}$ & Richardson et al, 2011 (167) \\
\hline $17-\mathrm{AAG}+$ trastuzumab & $\begin{array}{l}\text { Significant anticancer activity in patients with HER-2-positive, } \\
\text { metastatic breast cancer previously progressing on trastuzumab }\end{array}$ & Modi et al, 2011, (168) \\
\hline 17-AAG & $\begin{array}{l}\text { Further study not recommended (metastatic or locally advanced, } \\
\text { unresectable breast cancer) }\end{array}$ & Gartner et al, 2012 (169) \\
\hline 17-AAG & $\begin{array}{l}\text { Study endpoints were not reached because of early termination } \\
\text { (further study in melanoma should be considered) }\end{array}$ & Pacey et al, 2012 (170) \\
\hline STA-9090 & $\begin{array}{l}\text { Activity in NSCLS patients, particularly among those with ALK } \\
\text { rearrangements }\end{array}$ & Socinski et al, 2013 (171) \\
\hline IPI-504 + trastuzumab & $\begin{array}{l}\text { Modest clinical activity in patients with advanced or metastatic } \\
\text { HER-2-positive breast cancer }\end{array}$ & Modi et al, 2013 (172) \\
\hline STA-9090 & $\begin{array}{l}\text { Activity was observed in trastuzumab-refractory HER2-positive } \\
\text { and TNBC cancer patients }\end{array}$ & Jhaveri et al, 2014 (173) \\
\hline
\end{tabular}

Debio 0932 (2 trials), XL888 (2 trials), BIIB028 (1 trial) and DS-2248 (1 trial). The outcome of phase I clinical trials with Hsp90 inhibitors are well summarized in reviews of Jhaveri et al $(34,35)$. For detailed published results of phase II studies see Table I.

\section{Inhibitors of the C-terminal ATP binding pocket}

Unsatisfactory, results with N-terminal inhibitors in experimental and clinical trials arising from the increased toxicity and resistance induced by heat shock response led to development and characterization of a novel C-terminal inhibitors of Hsp90. Novobiocin (antiobiotic of coumarin group) and its analogues (clorobiocin and coumermycin A1) have been generated as agents for the treatment of bacterial infections with multi-resistant gram-positive bacteria such as Staphylococcus aureus and $S$. epidermidis $(36,37)$. Coumarin antibiotics were reported to bind strongly to gyrase B (DNA topoisomerase II) (38) but also weakly to the Hsp90 C-terminal nucleotidebinding site (39) followed by induced degradation of Hsp90 client proteins such as v-Src, Raf-1, ErbB2 and mutant p53 (39). Moreover, novobiocin disrupted the interaction of both the cochaperons p23 and Hsp70 with the Hsp90 complex (40). Structural modification of this compound has led to analogues with 1,000-fold greater efficacy in antiproliferative assays against various cancer cell lines (41-43). In this regard, 3-aminocoumarin analogue with introduced tosyl substituent on $\mathrm{C}-4$ position of coumarin nucleus (4TCNA) promoted apoptosis through activation of caspases 7 and 8 in MCF-7 human breast cancer cells. Furthermore, 4TCNA induced cleavage of p23 which plays an important role in activity of number of transcription factors of steroids/thyroid receptors family (40). The same group of scientists identified a new family of novobiocin analogues in which the coumarin unit was replaced by a 2-quinoleinone moiety. Compound 4-tosyl3[(chroman-6-yl)carboxylamino]-2-quinolon (4TCCQ) was 100 -fold more potent than the parental natural novobiocin and 6-fold more active than the synthetic analogue 4TCNA. Additionally, 4TCCQ induced the degradation of estrogen receptor $\alpha$ and strongly induced the cell death in MCF-7 cells (40). Compound A4, lacking the 4-hydroxyl of the coumarin moiety and containing an $\mathrm{N}$-acetyl side chain in lieu of the benzamide, was the most active compound, which induced degradation of Hsp90-dependent client proteins at 70-fold lower concentration than novobiocin (40). 4-hydroxy moiety of the coumarin ring and the 3'-carbamate of the noviose appendage were detrimental to Hsp90 inhibitory activity. In an effort to confirm these findings, 4-deshydroxy novobiocin (DHN1) and 3'-descarbamoyl-4-deshydroxynovobiocin (DHN2) were prepared and evaluated against Hsp90. Both compounds were significantly more potent than the natural product (44). 
Novel novobiocin-derived C-terminal Hsp90 inhibitor KU135 induced antiproliferative effects in Jurkat T-lymphocytes, caused the degradation of known Hsp90 client proteins and revealed more potent antiproliferative effects than the known N-terminal Hsp90 inhibitor 17-AAG. Moreover, KU135 in comparison to 17-AAG was found to be a potent inducer of mitochondria-mediated apoptosis as evidenced, in part, by the fact that cell death was inhibited to a similar extent by $\mathrm{Bcl}-2 / \mathrm{Bcl}-\mathrm{x}_{\mathrm{L}}$ overexpression or the depletion of apoptotic protease-activating factor-1 (Apaf-1). Intriguingly, KU135 did not induce upregulation of Hsp70 and Hsp90 in Jurkat T-lymphocytes (45). The study of Samadi et al (46) demonstrated similar effect of KU135 in most melanoma cells, where it reduced cell survival, proliferation, and induced apoptosis more significantly than 17-AAG. Additionally, levels of Hsp90 and Hsp70 did not increase, while the levels of phosphorylated HSF-1 levels decreased after KU135 treatment of melanoma cells. KU135 inhibited cell proliferation by regulating signaling pathways, which are different from those targeted by 17-AAG and as such represents a novel opportunity for Hsp90 inhibition. In this regard, KU135 seems to be a potential candidate for cancer therapy against melanoma. Recently developed C-terminal Hsp90 inhibitor KU174 exhibited very robust antiproliferative and cytotoxic activity together with client protein degradation and disruption of Hsp90 native complexes without induction of an HSR in prostate cancer cells. In a pilot in vivo proof-of-concept study KU174 demonstrated efficacy at $75 \mathrm{mg} / \mathrm{kg}$ in a PC3-MM2 rat tumor model (47).

Furthermore, novel novobiocin analogue F-4 as a putative C-terminal inhibitor of Hsp90 also demonstrated improved potency and efficacy compared to novobiocin in antiproliferative assays and decreased the expression of client proteins. Prostate specific antigen (PSA) secretion was inhibited in a dose-dependent manner that paralleled a decrease in androgen expression (AR). In addition, superior efficacy was demonstrated by F-4 compared to 17-AAG in experiments measuring cytotoxicity and apoptosis (48). Recently, assisted by molecular docking studies, a scaffold containing a biphenyl moiety in lieu of the coumarin ring system found in novobiocin, was identified for development of new Hsp90 C-terminal inhibitors. A library of small molecules containing the biphenyl moiety was designed, synthetised, and evaluated against two breast cancer cell lines with good antiproliferative activity manifested (49).

The most abundant polyphenolic catechin with chemopreventive and anticancer activities is epigallocatechin-3-gallate (EGCG) (50). Palermo et al (51) demonstrated that EGCG can inhibit the transcriptional activity of aryl hydrocarbon receptor (AhR) through a mechanism involving direct binding to the C-terminal region of Hsp90. A novel Hsp90 inhibitor impaired the association of $\mathrm{Hsp} 90 / \mathrm{Hsc70}$ and $\mathrm{Hsp} 90 / \mathrm{p} 23$, by directly binding to the C-terminal region of Hsp90, inhibited Hsp90 chaperoning function, and simultaneously degraded multiple cancer-related Hsp90 client proteins $(52,53)$. EGCG specifically inhibited the expression of Hsp70 and Hsp90 by inhibiting the promoter activity of Hsp70 and Hsp90. Pretreatment with EGCG increased the stress sensitivity of MCF-7 cells upon heat shock $\left(44^{\circ} \mathrm{C}\right.$ for $\left.1 \mathrm{~h}\right)$ or oxidative stress $\left(\mathrm{H}_{2} \mathrm{O}_{2}, 500 \mu \mathrm{M}\right.$ for $\left.24 \mathrm{~h}\right)$. Moreover, treatment with EGCG $(10 \mathrm{mg} / \mathrm{kg})$ in a xenograft model resulted in delayed tumor incidence and reduced tumor size, as well as the inhibition of Hsp70 and Hsp90 expression (54).

\section{Combination of Hsp90 inhibitor with second therapy}

The interaction of survival signals that occured as side effects of treatments could be very effectively limited through combination of therapies. In this regard, Hsp90 inhibitors may be a promising strategy e.g., to sensitize cisplatin-resistant Fancony anemia pathway-proficient tumor cells to cisplatin (55), to overcome autophagy, a mechanism protecting rhabdomyosarcoma cells from drug-induced cytotoxicity (56), to sensitize human tumors to irradiation (57) or simply to enhance the effect of therapy when combined with the non-genotoxic Hsp90 inhibitor (58).

Oral, esophageal, gastrointestinal, colon and pancreatic cancer. The Hsp90 inhibitor 17-AAG enhanced significantly the radiation sensitivity and induced apoptosis in oral squamous cell carcinoma cell line SAS/neo which has a wild-type p53. On the other hand, the radiation sensitizing effect of 17-AAG was limited in the SAS/Trp248 cells which has a mutated p53 (59). 17-AAG was also shown to inhibit ATP-binding cassette sub-family G member 2 (ABCG2) upregulation, thereby reversing the $\mathrm{ABCG} 2$-mediated multidrug resistance (MDR) and in this regard can be used as a chemosensitizer for the treatment of esophageal cancer (60). Furthermore, 17-AAG sensitized esophageal cancer cells to $\gamma$-photon radiation, probably through its ability to affect a range of signalling components simultaneously, for example both EGF and IGF-1 (61).

Hsp90 inhibitors, IPI-493 as well as IPI-504, revealed antitumor activity and induced receptor tyrosine kinase KIT downregulation in xenograft model of gastrointestinal stromal tumor (GIST) with heterogeneous KIT mutations $(62,63)$. IPI-493 synergized with tyrosine kinase inhibitors, that are commonly used for the treatment of advanced or imatinibresistant GIST (63). Treatment effects of IPI-504 were also enhanced and/or more potent in combination with imatinib or sunitinib (62). Similarly a combination of imatinib and Hsp90 inhibitor AT13387 treatment in the imatinib-resistant GIST430 model significantly enhanced tumor growth inhibition over the monotherapies. These results, as well as good tolerance of AT13387, suggest this Hsp90 inhibitor as an excellent candidate for clinical testing in gastrointestinal stromal tumors in combination with imatinib (64). Moreover, by blocking Hsp90, Lang et al (65) disrupted rapamycin-induced activation of alternative signaling pathways in hepatocellular carcinoma and substantially improved the growth-inhibitory effects of mTOR inhibition in vivo.

Hsp90 inhibition may be also an attractive target for innovative treatment of gastroenteropancreatic neuroendocrine tumors alone or in combination with either IGF-1R or mTOR inhibitors (66). Unusually, Hsp90 inhibitor 17-AAG was more responsive in colon cancer cells with $\mathrm{BRAF}^{\mathrm{V} 600 \mathrm{E}}$ mutation than selective BR AF ${ }^{\mathrm{V} 600 \mathrm{E}}$ inhibitor PLX4720, probably due to the multiple oncogenic proteins that are Hsp90 clients (67). Indeed, the inhibition of Hsp90 with 17-DMAG abrogated the invasive properties of colon cancer cells and modulated the expression of the antimetastatic factor acti- 
vating transcription factor-3 and improved the efficacy of oxaliplatin (68). Furthermore, 17-AAG interventions directed to cell cycle arrest in G1 may potentiate oxaliplatin activity in colon cancer cells with impaired p53 (69) and may be critical for its ability to reverse cisplatin resistance (70). Similarly, GA reversed topotecan induced upregulation of the anti-apoptotic protein Bcl-2 in both $\mathrm{p}^{+/+}$and $\mathrm{p} 53^{-/-}$HCT116 cells and sensitised human colon cancer cells to topoisomerase I poisons via depletion of key anti-apoptotic and cell cycle checkpoint proteins (71). On the other hand, the combination of an active metabolite of irinotecan SN-38 and 17-AAG was shown to be synergistic in p53-null, but not in parental HCT116 cells by median effect. Taken together, 17-AAG specifically inhibited the $\mathrm{G}(2) / \mathrm{M}$ checkpoint in p53-defective cells by downregulation of checkpoint kinases Chk1 and Wee1 (72). Similarly, GA enhanced the effect of ionizing radiation in p53 and p21 null cells (73).

The inhibition of Hsp90 with GA destabilised Cdc25A independent of Chk1/2, whereas the standard drug for pancreas carcinoma treatment, gemcitabine caused Cdc25A degradation through the activation of Chk2. Both agents applied together additively inhibited the expression of Cdc25A and the proliferation of pancreatic carcinoma cells, as well as reduced the resistance of pancreatic carcinoma cells to treatment with gemcitabine (74). Indeed, the combined therapy of 17-DMAG and Akt inhibitor perifosine overcame tumor growth and resistance induced by bone marrow stromal cells and endothelial cells as well as the proliferative effect of exogenous interleukin-6, insulin-like growth factor-I, and vascular endothelial growth factor. The combination induced also apoptosis and growth inhibition in endothelial cells and inhibited angiogenesis (75). Moreover, short interfering RNA (siRNA) was used to knockdown ErbB3 in the resistant cell line AsPC1. Whereas individual treatments with siRNA to ErbB3 or 17DMAG had no effect on radiosensitivity, the combination, which reduced both ErbB2 and ErbB3, resulted in a significant enhancement in AsPC1 radiosensitivity (76). Interestingly, the dietary component from broccoli and broccoli sprouts sulforaphane also potentiated the efficacy of 17-AAG against pancreatic cancer through enhanced abrogation of Hsp90 function (77). For the complete list of oral, esophageal, pancreatic, gastrointestinal and colon cancer cell response to combination of Hsp90 inhibitor and other therapy (treatment) in vitro and/or in vivo see Table II.

Lung cancer. Hsp90 inhibitor IPI-504, induced tumor regression in aggressive $N f 1$-deficient malignancies and KRas/ p53-mutant lung cancer mouse models, but only when combined with rapamycin (78). Combinations of low-dose of non-ansamycin inhibitor of Hsp90, ganetespib (STA-9090 a unique resorcinolic triazolone) with MEK or PI3K/mTOR inhibitors, resulted in superior cytotoxic activity than single agents alone in a subset of mutant KRAS cells, and the antitumor efficacy of STA-9090 was potentiated by cotreatment with the PI3K/mTOR inhibitor BEZ235 in A549 xenografts in vivo (79). Similar combination of STA-9090 with paclitaxel, docetaxel or vincristine resulted in synergistic antiproliferative effects in the H1975 cells in vitro as wells as enhanced tumor growth inhibition observed in combination with paclitaxel and tumor regressions seen with docetaxel (80).
Furthermore, Hsp90 inhibitors have overcame the resistance to EGFR tyrosine kinase inhibitors in subcutaneous xenograft models of H1975 and A549 (81) and enhanced the antitumor activity of paclitaxel and camptothecin, respectively, in breast and colorectal tumor models (82). Hsp90 inhibition overcame the hepatocyte growth factor-triggered resitance to EGFR tyrosine kinase inhibitors and resulted in more successful treatment of patients with EGFR-mutant lung cancers (83). The effectiveness of combined therapy of EGFR tyrosine kinase inhibitors and Hsp90 inhibitors was also confirmed in the treatment of lung cancers co-driven by mutant EGFR containing T790M and MET $(84,85)$. Moreover, $17-A A G$ decreased the etoposide-induced p38 MAPK-mediated ERCC1 expression (DNA repair capacity) (86) and downregulated the cisplatin-induced thymidine phosphorylase (a key enzyme in pyrimidine nucleoside salvage pathway) expression and Erk1/2 and Akt activation (87) what sensitized lung cancer cells to etoposide and cisplatin, respectively.

Hsp90 inhibitors were also effective in treating crizotinibresistant tumors harboring secondary gatekeeper mutations within the ALK TK domain (88). Furthermore, Normant et al (89) observed partial responses to administration of IPI-504 as a single agent in a phase II clinical trial in patients with NSCLC, specifically in patients that carry an ALK rearrangement. The experimental data of Solit et al (90) suggested that Hsp90 inhibition in combination with chemotherapy may represent an effective treatment strategy for patients, whose tumors express EGFR kinase domain mutations, including those with de novo and acquired resistance to EGFR tyrosine kinase inhibitors. Acquired resistance limits the efficacy of ALK inhibitors, such as crizotinib and TAE684, however, combining inhibitors of ALK and Hsp90 resulted in synergistic cytotoxicity $(91,92)$.

Hsp90 inhibitor 17-DMAG, as well as purine-scaffold inhibitor PU-H71, were shown to be the most effective as radiosensitizer of lung cancer cells, when administered before radiation, because of its suppression of DNA repair at multiple levels, including BER and ATM-regulated pathways $(93,94)$. Recent results of Kim and Pyo (95) show that combined treatment of 17-AAG and celecoxib at clinically relevant concentrations may significantly enhance the therapeutic efficacy of ionizing radiation therapy. Moreover, very recent combination of 17-DMAG and histone deacetylase inhibitor belinostat synergistically inhibited in vitro proliferation of selected panel of 12 NSCLC cell lines. Importantly, both agents and their combination almost completely prevented TKI-resistant tumor formation (EGFR T790M mutation) in a xenograft model (96). For the above, and even further studies with the response of lung cancer cells to combination of Hsp90 inhibitor and another therapy see Table III.

Breast, ovary and prostate cancer. Hsp90 inhibitor IPI-504 resulted in a marked decrease in the levels of HER-2, Akt, p-Akt, and p-MAPK in trastuzumab-resistant xenografts as early as $12 \mathrm{~h}$ after a single dose of IPI-504 inhibitor. IPI-504-mediated Hsp90 inhibition may represent, together with other Hsp90 inhibitors, a novel therapeutic approach in HER-2 overexpressing and/or trastuzumab refractory HER-2positive cancer (97-100), and provide a promising strategy to overcome the development of resistance against trastuzumab. 
Table II. The response of oral, esophageal, pancreatic, gastrointestinal and colon cancer cells to combination of Hsp90 inhibitor with another therapy in vitro and/or in vivo.

\begin{tabular}{|c|c|c|c|c|c|}
\hline Cancer & Hsp90 inhibitor & Second therapy & Conditions & Tumor response & (Ref.) \\
\hline Oral squamous & $17-\mathrm{AAG}$ & Ionizing radiation & In vitro & $\uparrow$ p53-dependent & $(59)$ \\
\hline Esophageal & 17-AAG & Ionizing radiation & In vitro & $\uparrow$ & $(61)$ \\
\hline Esophageal & $17-\mathrm{AAG}$ & Cisplatin & In vitro & $\uparrow$ & $(174)$ \\
\hline Esophageal & Radicicol & Heat & In vitro & $\uparrow$ & $(175)$ \\
\hline Pancreatic & GA & 5-Fluorouracil & In vitro & $\begin{array}{l}\uparrow \text { in presence } \\
\text { of serum }\end{array}$ & $(176)$ \\
\hline Pancreatic & GA & Gemcitabine & In vitro & $\uparrow$ & (74) \\
\hline Pancreatic & GA, 17-AAG & 3-Bromopyruvate & In vitro, in vivo & $\uparrow$ & $(177,178)$ \\
\hline Pancreatic & 17-AAG & U0126 & In vitro & $\uparrow$ & $(179)$ \\
\hline Pancreatic & 17-AAG & Sulforaphane & In vitro, in vivo & $\uparrow$ & $(77)$ \\
\hline Pancreatic and other & 17-DMAG & Ionizing radiation & In vitro & $\begin{array}{c}\uparrow \text { predicted by ErbB3 } \\
\text { expression }\end{array}$ & $(76)$ \\
\hline Hepatocellular & 17-DMAG & Rapamycin & In vitro, in vivo & $\uparrow+$ ECs, and VSMCs & $(65)$ \\
\hline Pancreatic, glioblastoma & NVP-HSP990 & $\begin{array}{l}\text { Ionizing radiation, } \\
\text { hyperthermia }\end{array}$ & In vitro & $\uparrow$ & $(180)$ \\
\hline Gastrointestinal stromal & IPI-504 & Imatinib, sunitinib & In vivo & $\uparrow$ & $(62)$ \\
\hline Gastroentero-pancreatic & IP-504 & $\begin{array}{l}\text { IGF1R and mTOR } \\
\text { inhibitors }\end{array}$ & In vitro, in vivo & $\uparrow$ & $(66)$ \\
\hline Gastrointestinal stromal & IP-493 & Imatinib, sunitinib & In vivo & $\uparrow$ & $(63)$ \\
\hline Gastrointestinal stromal & AT13387 & Imatinib & In vitro, in vivo & $\uparrow$ & $(64)$ \\
\hline Colon & GA & Ionizing radiation & In vitro & $\begin{array}{c}\uparrow \text { in p53 compromised } \\
\text { cells }\end{array}$ & (73) \\
\hline Colon & GA & Topotecan & In vitro & $\uparrow$ p53-independent & $(71)$ \\
\hline Colon and other & GA & Ionizing radiation & In vitro & $\begin{array}{l}\uparrow \text { more in SQ-5 than } \\
\text { in DLD-1 cells }\end{array}$ & $(181)$ \\
\hline Colon & 17-AAG & TRAIL & In vitro & $\begin{array}{l}\uparrow \text { greater in TRAIL- } \\
\text { resistant cells }\end{array}$ & $(182)$ \\
\hline Colon & 17-AAG & AHA1 siRNA & In vitro & $\uparrow$ & $(183)$ \\
\hline Colon & 17-AAG & Cisplatin & In vitro & $\begin{array}{l}\uparrow \text { in cells with } \\
\text { sustained JNK }\end{array}$ & $(70)$ \\
\hline Colon & 17-AAG & Oxaliplatin & In vitro & $\uparrow$ in p53 deficient cells & $(69)$ \\
\hline Colon & 17-AAG & Irinotecan SN-38 & In vitro & $\uparrow$ in p53 defective cells & $(72)$ \\
\hline Colon & 17-AAG & TRAIL & In vitro & $\begin{array}{c}\uparrow \text { in BRAF (V600E) } \\
\text { mutant cells }\end{array}$ & $(67,184)$ \\
\hline Colon and other & 17-AAG & Nutlin & In vitro, in vivo & $\uparrow$ & $(58)$ \\
\hline Colon & 17-DMAG & Oxaliplatin & In vitro, in vivo & $\uparrow$ in p53 deficient cells & $(68)$ \\
\hline Colon & STA-9090 & $\begin{array}{l}\text { Ionizing radiation, } \\
\text { 5-fluorouracil }\end{array}$ & In vitro, in vivo & $\uparrow$ & $(185)$ \\
\hline
\end{tabular}

The symbol $\uparrow$ means at least the additive effect of the combination compared to single therapies. 
Table III. The response of lung cancer cells to combination of Hsp90 inhibitor with another therapy in vitro and/or in vivo.

\begin{tabular}{|c|c|c|c|c|c|}
\hline Cancer & Hsp90 inhibitor & Second therapy & Conditions & Tumor response & (Ref.) \\
\hline NSCLC & 17-AAG & Paclitaxel & In vitro & $\begin{array}{l}\uparrow \text { in cells with high } \\
\text { levels of p185 }\end{array}$ & $(186)$ \\
\hline NSCLC & 17-AAG & Cisplatin & In vitro & $\uparrow$ & $(87)$ \\
\hline NSCLC & 17-AAG & Etoposide & In vitro & $\uparrow$ & $(86)$ \\
\hline NSCLC & 17-AAG & VER-155008 & In vitro & $\uparrow$ & $(187)$ \\
\hline NSCLC & 17-DMAG & Ionizing radiation & In vitro & $\uparrow$ & $(93)$ \\
\hline NSCLC & 17-DMAG & PTACH, belinostat & In vitro, in vivo & $\uparrow$ & $(96,188)$ \\
\hline NSCLC & 17-DMAG & WZ4002 & in vivo & $\begin{array}{l}\uparrow \text { in EGFR }(\mathrm{T} 790 \mathrm{M}) \\
\text { mutant cells }\end{array}$ & $(84)$ \\
\hline NSCLC & 17-DMAG & Velcade & In vitro & $\uparrow$ & $(189)$ \\
\hline NSCLC & STA-9090 & $\begin{array}{l}\text { Paclitaxel, docetaxel, } \\
\text { vincristine }\end{array}$ & In vitro, in vivo & $\uparrow$ & $(80)$ \\
\hline NSCLC & STA-9090 & BEZ235 & In vitro, in vivo & $\uparrow$ in KRAS mutant cells & $(79)$ \\
\hline NSCLC & STA-9090 & Crizotinib & In vitro, in vivo & $\begin{array}{l}\uparrow \text { in ALK- and MET- } \\
\text { driven cells }\end{array}$ & $(92,190,191)$ \\
\hline NSCLC & $\begin{array}{l}\text { SNX-2112 } \\
\text { STA-9090 }\end{array}$ & Erlotinib & In vitro, in vivo & $\begin{array}{c}\uparrow \text { in wild-type or mutant } \\
\text { EGFR (L858R, T790M) } \\
\text { cells }\end{array}$ & $(85,192)$ \\
\hline NSCLC & CH5164840 & Erlotinib & In vitro, in vivo & $\begin{array}{c}\uparrow \text { in EGFR overexpressed } \\
\text { and mutant cells }\end{array}$ & $(193)$ \\
\hline NSCLC & CUDC-305 & Paclitaxel & In vitro, in vivo & $\begin{array}{l}\uparrow \text { in EGFR (T790M) or } \\
\text { KRAS mutant cells }\end{array}$ & $(81)$ \\
\hline NSCLC & WK88-1 & Gefitinib & In vitro, in vivo & $\uparrow$ in MET-driven cells & $(194)$ \\
\hline Lung & GA & TRAIL & In vitro & $\begin{array}{c}\uparrow \text { in TRAIL-resistant cells; } \\
\text { adverse effects of } \\
\text { high-dose GA }\end{array}$ & $(195)$ \\
\hline Lung and other & GA, 17-AAG & $\begin{array}{l}\text { Ionizing radiation, } \\
\text { celecoxib }\end{array}$ & In vitro, in vivo & $\uparrow$ in transformed cells only & $(95,196-198)$ \\
\hline Lung & 17-AAG & Paclitaxel & In vitro, in vivo & $\uparrow$ in EGFR mutant cells & (199) \\
\hline Lung and other & 17-AAG & $\begin{array}{l}\text { Smac mimetic } \\
\text { compound } 3\end{array}$ & In vitro & $\uparrow$ & $(200)$ \\
\hline Lung & 17-DMAG & Crizotinib & In vitro & $\begin{array}{c}\uparrow \text { EML4-ALK-expressing } \\
\text { cells }\end{array}$ & $(91)$ \\
\hline Lung & IP-504 & Rapamycin & In vitro, in vivo & $\uparrow$ in RAS- driven cells & $(78)$ \\
\hline Lung & PU-H71 & Ionizing radiation & In vitro & $\uparrow$ & (194) \\
\hline
\end{tabular}

The symbol $\uparrow$ means at least the additive effect of the combination compared to single therapies. NSCLC, non-small cell lung cancer.

Very promising strategy to overcome the development of trastuzumab resistance in breast cancer patients seems to be a combination of the Hsp90 inhibitor and histone deacety- lase 6 inhibitor carbamazepine (101). GA synergized with carbamazepine to promote HER-2 degradation and inhibited breast cancer cell proliferation. Solit et al (102) found that 
the inhibition of Hsp90 function sensitized breast cancer xenografts to Taxol through downregulation of Akt kinase. Hsp90 inhibitors may be an effective therapy also to treat aromatase inhibitor-resistant breast cancers and improved efficacy can be achieved by combined use of an Hsp90 inhibitor and an Akt inhibitor $(103,104)$. Moreover, Pashtan et al (105) demonstrated that Hsp90 inhibitor 17-AAG inhibiting multiple signaling activators including ErbB and Src kinases, it does not permit oncogene switching and resulted in a more prolonged and robust inhibition of downstream signaling pathways in breast cancer cells, than the individual tyrosine kinase inhibitors. In this way, Hsp90 inhibitors can prevent breast cancer cells from tyrosine kinase inhibition (105). Another way, to sensitize cancer cells is elimination of RIP1 protein, which can support cell survival due to activation of NF- $\kappa \mathrm{B}$. In this regard, 17-DMAG markedly reduced RIP1 expression and sensitized breast tumor cells to tumor necrosis factor-related apoptosis-inducing ligand (TRAIL)-induced apoptosis (eliminate the resistance to TRAIL) (106). A recent study of Stecklein et al (107) demonstrated the role of BRCA1, which is associated with the resistance to platinumbased chemotherapeutics and poly(ADP ribose) polymerase (PARP) inhibitors in regulating damage-associated checkpoint and repair responses to Hsp90 inhibitors. The above study pointed out BRCA1 as a clinically relevant target for enhancing sensitivity in refractory and/or resistant malignancies. Furthermore, complete regression of aggressive breast tumors in mice was observed after the combination of anti-angiogenic stress imposed by loss of Id protein and the inactivation of the HIF-1 $\alpha$ chaperone Hsp90 (108).

Interestingly, ovarian cancer cells overexpressing HER2 showed 5-fold increased sensitivity to the Hsp90 molecular chaperone inhibitor GA. In contrast, HER2-overexpressing cells showed statistically significant resistance to cisplatin, PI3K inhibitor LY294002 and tyrosine kinase inhibitor emodin (109). On the other hand, GA and 17-AAG may sensitize ovarian cancer cells to cisplatin (110) and paclitaxel (111), respectively, particularly those tumors in which resistance is driven by HER-2 and/or p-Akt.

Pharmacological inhibition of the cell cycle-dependent kinase (essential for G2-M checkpoint) Weel and its molecular silencing with siRNA uniformly increased apoptotic activity of the Hsp90 inhibitor 17-AAG in vitro (112). Moreover, Wee1 inhibition synergized with any one of the clinically evaluated Hsp90 inhibitors to inhibit an androgen-independent and invasive human prostate carcinoma cell line PC3 in vitro and in vivo (113). Hsp90 inhibitors trigger a heat shock response associated with increased expression of Hsp90, Hsp70, Hsp27, and clusterin that attenuates drug effectiveness in the treatment of castrate-resistant prostate cancer. However, clusterin inhibitor OGX-011 revealed markedly potentiated antitumor efficacy in xenograft models of human castrateresistant prostate cancer, leading to an $80 \%$ inhibition of tumor growth with prolonged survival compared with Hsp90 inhibitor monotherapy (114). Furthermore, administration of 17-AAG maintained androgen-sensitivity, prevented nuclear localization of endogenous androgen receptor and delayed the progression of LuCaP35 xenograft tumors to castration resistance. Thus, it appears that targeting Hsp90 may lead to new approaches to prevent and/or treat castration-resistant prostate cancer (115). Alternatively, co-administration of hyperthermia and 17-AAG released from plasmonic matrices was a powerful approach for the ablation of malignant cells and can be used in the form of similar combinations of nanoparticles and chemotherapeutic drugs for a variety of malignancies (116). For the complete list of breast, ovarian and prostate cancer cell response to combination of Hsp90 inhibitor and another therapy (treatment) in vitro and/or in vivo see Table IV.

Multiple myeloma, lymphocytic and myelogenous leukemia. Lamottke et al (117) demonstrated that inhibition of Hsp90 by small molecular mass inhibitors induced cell death in multiple myeloma. They analyzed the effects of the novel, orally bioavailable Hsp90 inhibitor NVP-Hsp990 on multiple myeloma cell proliferation and survival. NVP-Hsp990 inhibitor led to a significant reduction in myeloma cell viability and induced G2 cell cycle arrest, degradation of caspase- 8 and caspase-3, and induction of apoptosis. Inhibition of the Hsp90 ATPase activity was accompanied by the degradation of multiple myeloma phospho-Akt and phospho-Erk1/2 and upregulation of Hsp70. In this regard, PI3K/mTOR inhibitor in combination with NVP-Hsp990 mentioned above, rendered the Hsp90 blockade-mediated stress response ineffective and considerably increased the anti-multiple myeloma toxicity (118). Similarly, Chatterjee et al (119) demonstrated that the knockdown of Hsp72 and/or Hsp73 or treatment with VER-155008, decreased protein levels of Hsp90-chaperone clients affecting multiple oncogenic signaling pathways, and acted synergistically with the novel Hsp90 inhibitor NVP-AUY922 in myeloma cell death induction. Inhibition of the PI3K/Akt/GSK3 $\beta$ pathway with siRNA or PI103 decreased expression of the heat shock transcription factor 1 and downregulated constitutive and inducible Hsp70 expression (119). Moreover, NVP-AUY922 in combination with histone deacetylase inhibitors SAHA, NVP-LBH589, melphalan or doxorubicin resulted in synergistic inhibition of viability, with strong synergy (combination index $<0.3$ ) in the case of melphalan. Importantly, resistance of the RPMI-8226 cell line and relative resistance of some primary myeloma cells against NVP-AUY922 could be overcome by combination treatment (120). In this manner, the p38 MAPK inhibitor BIRB 796, inhibited protein expression and phosphorylation of Hsp27 induced by Hsp90 inhibitor 17-AAG and enhanced its cytotoxicity (121). Transcription induction of Hsps in response to $17-\mathrm{AAG}$ was also inhibited by the transcription inhibitor actinomycin D. Thus, the combination strategy of 17-AAG and actinomycin D represents a potential approach for the treatment of hematological malignancies (23).

Furthermore, Hsp90 is a promising therapeutic target also in JAK-2 driven cancer, e.g., myeloproliferative neoplasms, B cell acute lymphoblastoid leukemia, including those with genetic resistance to JAK enzymatic inhibitors $(122,123)$. Intriguingly, Hsp90 inhibitor-based antileukemia therapy may override de novo or acquired resistance of acute myelogenous leukemia cells to pan-histone deacetylase inhibitors (124). On the contrary, clinically tolerable doses of tanespimycin (17-AAG) had little effect on resistance-mediating client proteins in relapsed leukemia and exhibits limited activity in combination with cytarabine (Clinicaltrials.gov identifier: NCT00098423) (125). 
Table IV. The response of breast, ovarian and prostate cancer cells to combination of Hsp90 inhibitor with another therapy in vitro and/or in vivo.

\begin{tabular}{|c|c|c|c|c|c|}
\hline Cancer & Hsp90 inhibitor & Second therapy & Conditions & Tumor response & (Ref.) \\
\hline Breast & GA & Carbamazepine & In vitro & $\uparrow$ & $(101)$ \\
\hline Breast & GA & Bortezomib & In vitro & $\uparrow$ & $(201)$ \\
\hline Breast & 17-AAG & Trastuzumab & In vitro & $\uparrow$ in high ErbB2 & $(202,203)$ \\
\hline Breast & 17-AAG & Rapamycin & In vitro & $\uparrow$ & $(204)$ \\
\hline Breast & 17-AAG & Taxol, doxorubicin & In vitro, in vivo & $\uparrow \mathrm{Rb}$-dependent & $(102,205)$ \\
\hline Breast & 17-AAG & Gefitinib & In vitro & $\uparrow$ & $(105)$ \\
\hline Breast & 17-AAG & Loss of Id protein & In vivo & Complete regression & $(108)$ \\
\hline Breast & 17-AAG & PDT-Photofrin, PDT-NPe6 & In vitro & $\uparrow$ & $(206)$ \\
\hline Breast and other & 17-AAG & Paclitaxel + rapamycin & In vitro, in vivo & $\uparrow$ & $(207)$ \\
\hline Breast & 17-DMAG & TRAIL & In vitro & $\uparrow$ & $(106)$ \\
\hline Breast & 17-DMAG & Triciribine & In vitro & $\uparrow$ & $(103)$ \\
\hline Breast & 17-DMAG & PDT-hypericin & In vitro & $\uparrow$ & $(208)$ \\
\hline Breast & IP-504 & Trastuzumab & In vitro, in vivo & $\uparrow$ & $(99)$ \\
\hline Breast & SNX-2112 & Trastuzumab & In vitro, in vivo & $\uparrow$ & $(100)$ \\
\hline Breast and other & CUDC-305 & Paclitaxel, camptothecin & In vitro, in vivo & $\uparrow$ & $(82)$ \\
\hline Breast and other & $\begin{array}{l}\text { CH5164840 } \\
\text { NVP-AUY922 }\end{array}$ & Trastuzumab, lapatinib & In vitro, in vivo & $\uparrow$ & $(97,98)$ \\
\hline Breast & NVP-AUY922 & AZD8055 & In vitro & $\uparrow$ & (209) \\
\hline Ovarian & GA & Cisplatin & In vitro & $\uparrow$ & $(110)$ \\
\hline Ovarian & 17-AAG & Carboplatin & In vitro, in vivo & $\uparrow$ beneficial in vivo & $(210)$ \\
\hline Ovarian & 17-AAG & Paclitaxel & In vitro & $\uparrow$ ErbB2,p-Akt-dependent & $(111)$ \\
\hline Prostate & GA & TRAIL & In vitro & $\uparrow$ & $(195)$ \\
\hline Prostate & 17-AAG & Cdc37 siRNA & In vitro & $\uparrow$ & $(211)$ \\
\hline Prostate & 17-AAG & Survivin siRNA & In vitro & $\uparrow$ & $(212)$ \\
\hline Prostate & 17-AAG & Wee1 siRNA & In vitro & $\uparrow$ & $(112)$ \\
\hline Prostate & $\begin{array}{l}\text { 17-AAG, } \\
\text { SNX-2112, } \\
\text { STA-9090 }\end{array}$ & Wee1 inhibitor & In vitro, in vivo & $\uparrow$ & $(113)$ \\
\hline Prostate & 17-AAG & Hyperthermia & In vitro & $\uparrow$ & $(116)$ \\
\hline Prostate & $\begin{array}{l}\text { 17-AAG } \\
\text { PF04928473 } \\
\text { PF04929113 }\end{array}$ & $\begin{array}{l}\text { Clusterin siRNA, } \\
\text { OGX-011, OGX-427 }\end{array}$ & In vitro, in vivo & $\uparrow$ & $(114,159)$ \\
\hline Prostate & 17-AAG & Castration & In vivo & $\uparrow$ & $(115)$ \\
\hline Prostate & NVP-AUY922 & Ionizing radiation & In vitro, in vivo & $\uparrow$ & $(213)$ \\
\hline Prostate & NVP-AUY922 & Docetaxel & In vivo & $\uparrow$ & $(214)$ \\
\hline
\end{tabular}

The symbol $\uparrow$ means at least the additive effect of the combination compared to single therapies. 
Table V. The response of multiple myeloma, lymphocytic and myelogenous leukemia cells to combination of Hsp90 inhibitor with another therapy in vitro and/or in vivo.

\begin{tabular}{|c|c|c|c|c|c|}
\hline Cancer & Hsp90 inhibitor & Second therapy & Conditions & Tumor response & (Ref.) \\
\hline Myeloma & GA & Apigenin & In vitro & $\uparrow$ & $(215)$ \\
\hline Myeloma & 17-AAG & GRN163L & In vitro, in vivo & $\uparrow$ & $(216)$ \\
\hline Myeloma & 17-AAG & Bortezomib & In vitro & $\uparrow$ & $(217)$ \\
\hline Myeloma & 17-AAG & Rapamycin & In vitro & $\uparrow$ & $(218)$ \\
\hline Myeloma & 17-AAG & 8-chloro-adenosine & In vitro & $\uparrow$ & $(219)$ \\
\hline Myeloma & 17-AAG & Actinomycin D & In vitro & $\uparrow$ & $(23)$ \\
\hline Myeloma & 17-AAG & BIRB 796 & In vitro & $\uparrow$ & $(121)$ \\
\hline Myeloma & 17-DMAG & Perifosine & In vitro & $\uparrow+$ BM microenvir. & $(75)$ \\
\hline Myeloma & IPI-504 & Bortezomib & In vitro, in vivo & $\uparrow$ & $(220)$ \\
\hline Myeloma & NVP-AUY922 & $\begin{array}{l}\text { NVP-LBH589 and SAHA, } \\
\text { melphalan, doxorubicin }\end{array}$ & In vitro & $\uparrow$ & $(120)$ \\
\hline Myeloma & NVP-AUY922 & Hsp72/73 siRNA, PI103 & In vitro & $\uparrow$ & $(119)$ \\
\hline Myeloma & NVP-AUY922 & Triptolide & In vitro & $\uparrow$ & $(221)$ \\
\hline Myeloma & NVP-AUY922 & TG101209 & In vitro & $\uparrow$ & $(123)$ \\
\hline Myeloma & NVP-AUY922 & NVP_BVB808 & In vitro, in vivo & $\uparrow$ & $(122)$ \\
\hline Myeloma & NVP-HSP990 & Melphalan & In vitro & $\uparrow$ & $(117)$ \\
\hline Myeloma & NVP-HSP990 & PI3K/mTOR inhibitor & In vitro & $\uparrow$ & $(118)$ \\
\hline Leukemia & GA & Doxorubicin & In vitro & $\uparrow$ Bcr-Abl-dependent & $(130,222)$ \\
\hline Leukemia & GA & Flavopiridol & In vitro & $\uparrow$ & $(133)$ \\
\hline Leukemia & GA & $\begin{array}{l}\text { Herbimycin A, chlorambucil, } \\
\text { fludarabine }\end{array}$ & In vitro & $\uparrow$ & $(127)$ \\
\hline Leukemia & GA & Nutlin-3 & In vitro & $\uparrow$ p53 wild-type & $(223)$ \\
\hline Leukemia & 17-AAG & SAHA, SB & In vitro & $\uparrow$ & $(224)$ \\
\hline Leukemia & 17-AAG & $\mathrm{UCN}-01$ & In vitro & $\uparrow$ & $(225)$ \\
\hline Leukemia & 17-AAG & GTP14564 & In vitro & $\uparrow$ & $(226)$ \\
\hline Leukemia & 17-AAG & Cytarabine & In vitro & $\uparrow$ & $(227)$ \\
\hline Leukemia & 17-AAG & PKC412, LBH589 & In vitro & $\uparrow$ & $(228,229)$ \\
\hline Leukemia & 17-AAG & Imatinib & In vitro & $\uparrow$ & $(230)$ \\
\hline Leukemia & 17-AAG & KNK437, Hsp70 siRNA & In vitro & $\uparrow$ & $(160)$ \\
\hline Leukemia & 17-AAG & $\begin{array}{l}\text { Histone deacetylase } 6 \text { siRNA, } \\
\text { tubacin }\end{array}$ & In vitro & $\uparrow$ & $(231)$ \\
\hline Leukemia & 17-AAG & Rituximab & In vitro & $\uparrow$ & $(129)$ \\
\hline Leukemia & 17-DMAG & Dasatinib & In vitro & $\uparrow$ & $(232)$ \\
\hline Leukemia & IP-504 & Imatinib & In vivo & $\uparrow+$ leukemia stem cells & $(131)$ \\
\hline Leukemia & NVP-AUY922 & Cytarabine, fludarabine & In vitro, in vivo & $\uparrow$ & $(128,233)$ \\
\hline Leukemia & NVP-AUY922 & Nilotinib & In vitro, in vivo & $\uparrow$ & $(132)$ \\
\hline Leukemia & $\begin{array}{l}\text { NVP-AUY922 } \\
\text { SNX-7081 }\end{array}$ & Fludarabine & In vitro & $\uparrow$ & $(126,234)$ \\
\hline Lymphoma & 17-DMAG & Doxorubicin & In vitro & $\begin{array}{l}\uparrow \text { when } 17-\text { DMAG } \\
\text { after doxorubicin }\end{array}$ & $(235)$ \\
\hline Lymphoma & 17-DMAG & Vorinostat & In vitro & $\uparrow$ & $(236)$ \\
\hline Lymphoma & IPI-504 & $\begin{array}{l}\text { Akt/PI3K inhibitor, } \\
\text { doxorubicin }\end{array}$ & In vitro & $\uparrow$ & $(237)$ \\
\hline Lymphoma & IPI-504 & Bortezomib & In vitro & $\uparrow$ & $(134)$ \\
\hline
\end{tabular}

The symbol $\uparrow$ means at least the additive effect of the combination compared to single therapies. 
The Hsp90 inhibitor SNX-7081, which is significantly more potent than 17-AAG synergized and restored sensitivity to fludarabine in seven lymphocytic leukemia cell lines and 23 patient samples, including TP53 mutated cell lines and TP53 or ATM disfunctional patient cells (126). Similar sensitizing effect of Hsp90 inhibitor on chronic lymphocytic leukemia cells was demonstrated by Jones et al (127) as well as Walsby et al (128) who combined GA and NVP-AUY922, respectively, in combination with fludarabine. In this regard, Hsp90 inhibitors represent a potential treatment strategy for fludarabine refractory diseases. A novel strategy to enhance therapeutic response in chronic lymphocytic leukemia may also represent the combination of Hsp90 inhibitor and therapeutic antibody rituximab (129).

Both HL-60 cells transfected with Bcr-Abl and naturally $\mathrm{Ph} 1$-positive $\mathrm{K} 562$ leukemia cells are resistant to most cytotoxic drugs, but were found to be sensitive to GA. In this regard, GA sensitized Bcr-Abl-expressing cells to doxorubicin and paclitaxel. However, in parental HL-60 cells, GA antagonized the cytotoxic and cell death effects of doxorubicin included inhibition of PARP cleavage and nuclear fragmentation (130). Elimination of mutant BCR-ABL (T315I) kinase seems to be more effective therapeutic strategy for treating BCR-ABL-induced leukemia than the inhibition of BCR-ABL (T315I) kinase activity. Indeed, combination treatment with Hsp90 inhibitor IPI-504 and imatinib was more effective than either treatment alone in prolonging survival of mice simultaneously bearing both wild-type and T315I leukemic cells (131). Simultaneous exposure of BaF3 cells expressing BCR-ABL mutants including T315I to AUY922 and nilotinib was more effective at reducing the outgrowth of resistant cell clones as well as at survival prolongation of mice transplanted with mixture of $\mathrm{BaF} 3$ cells expressing wild-type BCR-ABL and mutant forms (132). Similarly, flavopiridol (semisynthetic flavone and selective inhibitor of CDKs) sensitized imatinibresistant HL/Bcr-Abl cells to GA and it seems that a cocktail of flavopiridol, 17-AAG (or its analogs) and imatinib may be an attractive approach for further investigations (133).

Despite the promising introduction of the proteasome inhibitor bortezomib in the treatment of mantle cell lymphoma (MCL), not all patients respond, and resistance often appears after initial treatment. In bortezomib-resistant cells, cell pretreatment with Hsp90 inhibitor IPI-504, led to synergistic induction of apoptotic cell death when combined with bortezomib (134). For the above, and further studies with a response of multiple myeloma, lymphocytic and myelogenous leukemia cells to combination of Hsp90 inhibitor and another therapy see Table V.

Glioblastoma multiforme. 17-AAG and PARP inhibitor olaparib had modest, replication-dependent radiosensitizing effects on T98G glioma cells. Additive radiosensitization was observed through the combination treatment, mirrored by increases in gammaH2AX foci in $\mathrm{G}(2)$-phase cells. Unlike olaparib, 17-AAG did not increase radiation sensitivity of Chinese hamster ovary cells, indicating tumor specificity (135). In addition, 17-AAG sensitized xenografted U87MG cells to cisplatin in nude mice. Indeed, Hsp90-targeted therapy seems to be an effective strategy for potentiating chemotherapy using DNA-crosslinking agents for temozolomide-refractory gliomas (136). Moreover, treatment with subtoxic doses of 17-AAG in combination with tumor necrosis factor-related apoptosis-inducing ligand (TRAIL) induced rapid apoptosis in TRAIL-resistant glioma cells, suggesting an attractive strategy for treating gliomas (137). Interestingly, 17-AAG inhibited the growth of intracranial tumors and synergized with radiation both in tissue culture and in intracranial tumors. On the contrary, 17-AAG did not synergize with temozolomide in any of glioma models (138). The response of glioblastoma cells to combination of Hsp90 inhibitor with other therapy is summarized in Table VI.

Melanoma.17-AAG induced in uveal melanoma cells compared to cutaneous melanoma cells (with low tyrosine kinase activity of ${ }^{\mathrm{WT}} \mathrm{B}-\mathrm{Raf}$ ) downregulation of ${ }^{\mathrm{WT}} \mathrm{B}-\mathrm{Raf}$ protein, followed by Mek/Erk inactivation and a decrease in cyclin D1. In this regard, the combination of 17-DMAG and imatinib mesylate was more efficient, than individual treatments of c-Kit positive uveal melanoma cells (21). The Hsp90 inhibitor XL888 increased Bcl-2 interacting mediator of cell death expression, decreased Mcl-1 expression, and induced apoptosis more effectively than dual mitogen-activated protein-extracellular signal-regulated in most resistant melanoma models. The reversal of the resistance phenotype was associated with the degradation of PDGFR $\beta$, COT, IGFR1, CRAF, ARAF, S6, cyclin D1 and Akt (139). Inhibition of Hsp90 by GA sensitized melanoma cells also to thermosensitive ferromagnetic particle-mediated by hyperthermia with temperature $43^{\circ} \mathrm{C}$ (140). The Hsp90 inhibitor ganetespib was reported to exhibit robust antitumor efficacy in preclinical model of BRAF ${ }^{\mathrm{V} 600 \mathrm{E}}$ melanoma and could thus readily overcome mechanisms of intrinsic and acquired resistance to selective BRAF inhibitors. The data mentioned above suggest that ganetespib may offer an alternative, and potentially complementary, strategy for therapeutic intervention in mutant BRAF-driven disease (141). The above studies are summarized in Table VII.

Bladder and renal cancer. Although up to $70 \%$ of advanced bladder cancer patients initially show good tumor response to systemic cisplatin-based combination chemotherapy, $>90 \%$ of good responders relapse and eventually die of the disease. This is attributable to the re-growth of bladder cancer-initiating cells, that have survived chemotherapy. These cancer-initiating cells were more resistant to cisplatin and exhibited more activity in the Akt and Erk oncogenic signaling pathways when compared with their CD44- counterparts. On the other hand, 17-DMAG simultaneously inactivated both Akt and Erk signaling and synergistically potentiated the cytotoxicity of cisplatin against bladder cancer-initiating cells by enhancing cisplatin-induced apoptosis in vitro and in vivo (142). Similarly, low doses of 17-DMAG potentiated antitumor activity of chemoradiotherapy (cisplatin + ionizing radiation) and supported clinical trial of Hsp90 inhibitors to overcome chemoradiotherapy resistance in patients with muscle-invasive bladder cancer (143). The combination of 17-AAG and HIV protease inhibitor ritonavir inhibited renal cancer growth through the inhibition of HSF-1 expression and downregulation of Hsp27, Hsp70 and Hsp90 induced by 17-AAG (144). Recently, Ma et al (145) demonstrated dual targeting of two chaperones Hsp90 and Hsp70 and their combination with conventional anticancer 
Table VI. The response of glioblastoma cells to combination of Hsp90 inhibitor with another therapy in vitro and/or in vivo.

\begin{tabular}{|c|c|c|c|c|c|}
\hline Cancer & Hsp90 inhibitor & Second therapy & Conditions & Tumor response & (Ref.) \\
\hline Glioblastoma & 17-AAG & $\begin{array}{l}\text { ZD1839, } \\
\text { LY294002 }\end{array}$ & In vitro & $\uparrow$ & $(238,239)$ \\
\hline Glioblastoma & 17-AAG & Enzastaurin & In vitro & $\uparrow$ & $(240)$ \\
\hline Glioblastoma & 17-AAG & TRAIL & In vitro & $\uparrow$ & (137) \\
\hline Glioblastoma & 17-AAG & $\begin{array}{l}\text { Cisplatin, 1,3-bis(2- } \\
\text { chloroethyl)-1- } \\
\text { nitrosourea }\end{array}$ & In vitro, in vivo & $\uparrow$ & (136) \\
\hline Glioblastoma & $\begin{array}{l}\text { 17-AAG } \\
\text { 17-DMAG }\end{array}$ & $\begin{array}{l}\text { Ionizing radiation, } \\
\text { temozolomide }\end{array}$ & In vitro, in vivo & $\begin{array}{c}\uparrow \text { to ionizing } \\
\text { radiation, but not } \\
\text { to temozolomide } \\
\uparrow \text { in glioma stem cells }\end{array}$ & $(136,138,241)$ \\
\hline Glioblastoma & 17-AAG & Ionizing radiation, olaparib & In vitro & $\uparrow$ & $(135)$ \\
\hline $\begin{array}{l}\text { Glioblastoma } \\
\text { and other }\end{array}$ & 17-DMAG & Ionizing radiation & In vitro, in vivo & $\uparrow$ & $(242)$ \\
\hline Glioblastoma & NVP-AUY922 & $\begin{array}{l}\text { PI3K/mTOR inhibitor, } \\
\text { Mek inhibitor }\end{array}$ & In vitro & $\uparrow$ & $(155)$ \\
\hline Glioblastoma & HSP990 & BKM120 & In vitro & $\begin{array}{l}\uparrow \text { independent } \\
\text { on PTEN/p53 }\end{array}$ & $(243)$ \\
\hline
\end{tabular}

The symbol $\uparrow$ means at least the additive effect of the combination compared to single therapies.

Table VII. The response of melanoma cells to combination of Hsp90 inhibitor with other therapy in vitro and/or in vivo.

\begin{tabular}{|c|c|c|c|c|c|}
\hline Cancer & Hsp90 inhibitor & Second therapy & Conditions & Tumor response & (Ref.) \\
\hline Melanoma & GA & Hyperthermia & In vitro, in vivo & $\uparrow$ & $(140)$ \\
\hline Melanoma & 17-DMAG & Imatinib mesylate & In vitro & $\begin{array}{l}\uparrow \text { in WT B-Raf uveal } \\
\text { melanoma cells }\end{array}$ & $(21)$ \\
\hline Melanoma & STA-9090 & TAK-733 & In vitro, in vivo & $\begin{array}{l}\uparrow \text { in melanoma cells with } \\
\text { BRAF(V600E) mutation }\end{array}$ & $(141)$ \\
\hline $\begin{array}{l}\text { Melanoma } \\
\text { and other }\end{array}$ & PU-H71 & Cisplatin, melphalan & In vitro & $\uparrow$ & $(244)$ \\
\hline Melanoma & XL888 & $\begin{array}{l}\text { Vemurafenib, } \\
\text { doxycycline }\end{array}$ & $\begin{array}{l}\text { In vitro, 3D } \\
\text { spheroids }\end{array}$ & $\uparrow$ & $(139)$ \\
\hline
\end{tabular}

The symbol $\uparrow$ means at least the additive effect of the combination compared to single therapies.

drugs as promising therapeutic option for patients with advanced bladder cancer. The response of bladder and renal cancer cells to combination of Hsp90 inhibitor with another therapy is summarized in Table VIII.

Head and neck cancer. The synthetic Hsp90 inhibitor BIIB021 revealed a strong antitumor effect in head and neck squamous cell carcinoma cells in vitro and in vivo. Its antitumor effect was higher than the effect of ansamycin-based Hsp90 inhibitor 17-AAG and when combined with radiation sensitized the efficacy of radiation therapy (146). The activation of multichaperone complex could be a resistance mechanism to the antiproliferative and apoptotic effects induced by tipifarnib (farnesyl transferase inhibitor) and that the combination of 
Table VIII. The response of bladder and renal cancer cells to combination of Hsp90 inhibitor with another therapy in vitro and/ or in vivo.

\begin{tabular}{lllrr}
\hline Cancer & \multicolumn{1}{c}{ Hsp90 inhibitor } & \multicolumn{1}{c}{ Second therapy } & Conditions & Tumor response \\
\hline Bladder & GA & DNA vaccine against p185 and Met & In vivo & $\uparrow$ \\
Bladder & 17-AAG & Pifithrin + chemotherapy & In vitro & (245) \\
Renal & 17-AAG & Ritonavir & In vitro, in vivo & $\uparrow$ \\
Bladder & 17-AAG, 17-DMAG & Cisplatin & In vitro, in vivo & $(145)$ \\
Bladder & 17-DMAG & Chemoradiotherapy & In vitro, in vivo & $(144)$ \\
\hline
\end{tabular}

The symbol $\uparrow$ means at least the additive effect of the combination compared to single therapies.

Table IX. The response of head and neck, neuroblastoma, osteosarcoma and other transformed cells to combination of Hsp90 inhibitor with another therapy in vitro and/or in vivo.

\begin{tabular}{|c|c|c|c|c|c|}
\hline Cancer & Hsp90 inhibitor & Second therapy & Conditions & Tumor response & (Ref.) \\
\hline $\begin{array}{l}\text { Head and neck squamous cells } \\
\text { overexpressing Hsp90 }\end{array}$ & GA & $\begin{array}{l}\text { Tipifarnib, } \\
\text { docetaxel }\end{array}$ & In vitro & $\begin{array}{c}\uparrow \text { after GA + tipifarnib } \\
\text { not after } \\
\text { GA + docetaxel }\end{array}$ & $(147)$ \\
\hline Head and neck squamous cells & 17-AAG & $\begin{array}{l}\text { Cisplatin, } \\
\text { nutlin-3a }\end{array}$ & In vitro, in vivo & $\begin{array}{l}\uparrow \text { depended on p53 } \\
\text { and MDMX }\end{array}$ & $(246)$ \\
\hline Head and neck squamous cells & BIIB021 & Ionizing radiation & In vitro, in vivo & $\uparrow$ & $(146)$ \\
\hline Neuroblastoma, osteosarcoma & GA & Cisplatin & In vitro & $\uparrow$ & $(247)$ \\
\hline Osteosarcoma & NVP-AUY922 & CDK inhibitor & In vitro & $\uparrow$ & $(248)$ \\
\hline SV40-transformed COS-7 cells & GA & Velcade & In vitro & $\uparrow$ & $(249)$ \\
\hline Ewing's sarcoma & 17-AAG & IGF1R inhibitor & In vitro, in vivo & $\begin{array}{l}\uparrow \text { in IGF1R- } \\
\text { positive cells }\end{array}$ & $(250)$ \\
\hline HeLa, B16, MCA205 cells & 17-DMAG & $\begin{array}{l}\text { Quinacrine, 9- } \\
\text { aminoacridine }\end{array}$ & In vitro, in vivo & $\uparrow$ & $(251)$ \\
\hline HeLa cells & 17-AAG & Ionizing radiation & In vitro & $\uparrow$ & $(252)$ \\
\hline Rhabdomyosarcoma & 17-DMAG & Bortezomib & In vitro & $\uparrow$ & $(56)$ \\
\hline Pediatric & SNX-2112 & Cisplatin & In vitro & $\uparrow$ & $(253)$ \\
\hline
\end{tabular}

The symbol $\uparrow$ means at least the additive effect of the combination compared to single therapies.

tipifarnib with GA is possibly a suitable therapeutic strategy in the treatment of Hsp90-overexpressing head and neck squamous cell cancers (147). Interestingly, the combination of GA with docetaxel was not able to induce any synergistic effects on cell growth inhibition of head and neck squamous cell cancers independently of Hsp90 expression and activation status. On the other hand, the combination of GA with tipifarnib was potentially able to give synergistic effects on the growth arrest of head and neck squamous cell cancers especially when Hsp90 was overexpressed and even more when it was over-activated (147). Sensitizing effect of Hsp90 inhibitor was demonstrated in many other transformed cells, the results of which are shown together with head and neck cancer cells in Table IX.
Stem cells. Recent studies of Lee et al (148) showed that the combination of GA with quercetin or KNK437 sensitized breast cancer stem-like cells characterized by high intracellular aldehyde dehydrogenase activity and higher expression of Hsp90 $\alpha$ toward antiproliferation and anti-migration effects of GA. Lee et al (148) also found that knockdown of Hsp27 could mimic the effect of Hsp inhibitors to potentiate the breast cancer stem-like cell targeting effect of GA. Newman et al (149) also supported the use of Hsp90 inhibitor as a cancer stem cell targeting agent and showed, that HSF-1 is an important target for elimination of both cancer and non cancer stem cells in cancer. They found, that low concentrations of the Hsp90 inhibitor 17-AAG eliminate lymphoma cancer stem 
cells in vitro and in vivo by disrupting the transcriptional function of HIF-1 $\alpha$ (149).

\section{Resistance to Hsp90 inhibitors}

Kelland et al (150) observed a positive relationship between $\mathrm{NAD}(\mathrm{P}) \mathrm{H}$ :quinone oxidoreductase (NQO1, DT-diaphorase) expression level and growth inhibition by 17-AAG. Stable, high-level expression of the NQO1 gene transfected into the DT-diaphorase-deficient (by NQO1 mutation) BE human colon carcinoma cell line resulted in a 32-fold increase in 17-AAG growth-inhibition activity. Increased sensitivity to $17-\mathrm{AAG}$ in the transfected cell line was also confirmed in xenografts (150). Low NQO1 activity could be a likely mechanism of acquired resistance to $17-\mathrm{AAG}$ in glioblastoma and melanoma. Indeed, Hsp90 inhibitors which avoid the liability of NQO1 metabolism are able to avoid the resistance due to decreased NQO1 activity and provide additional support for the clinical development of such structurally novel Hsp90 inhibitors (151). In this regard, the synthetic purine-scaffold Hsp90 inhibitor BIIB021, resorcinylic diaryl pyrazole CCT018159 as well as resorcinylic diaryl pyrazole/isoxazole amides VER-49009, VER-50589 or VER-52296 (NVP-AUY922 and AUY922) are promising Hsp90 inhibitors with several advantages compared to 17-AAG, including better solubility and independence from the effects of P-glycoprotein and NQO1 (151-153). Alongside depletion of client proteins, however, the BIIB021, VER-50589, VER-49009 and NVP-AUY922 all caused induction of Hsp72 and Hsp27 $(31,154,155)$. On the other hand, the upregulation of Hsp27 has a significant role in 17-AAG resistance, which may be mediated in part through GSH regulation. The modulation of GSH was able to enhance the efficacy of Hsp90-directed therapy in clinic (156). Sharp et al (157) demonstrated that thiadiazole inhibitors display a more limited core set of interactions relative to the clinical trial candidate NVP-AUY922 and consequently may be less susceptible to resistance derived through mutations in Hsp90, but these inhibitors also caused induction of the heat shock response with the upregulation of Hsp72 and Hsp27 protein expression.

\section{Combination of Hsp inhibitors}

The key, how to solve the problem of induced expression of heat shock proteins especially Hsp27 and Hsp70, after the treatment with Hsp90 inhibitors could be combined therapy of Hsp90 inhibitor and other Hsp inhibitors. Targeting multiple Hsps could likely shut down the heat shock response and associated rescue mechanisms, leading to low chemotherapeutic resistance (158). Dual therapy of combined Hsp inhibitors showed that Hsp27 inhibitors potentiate the effects of Hsp90 inhibitors and delay castrate-resistant prostate cancer $(114,159)$ as well as sensitize breast cancer stem-like cells (148). Moreover, KNK437 a benzylidine lactam inhibitor of Hsp70, attenuated 17-AAG-mediated Hsp70 induction and increased 17-AAG-induced apoptosis and loss of clonogenic survival of HL-60 cells (160). The overexpression of Hsp70 induced by 17-AAG or NVP-AUY922 inhibitors in cancer cells was counteracted considerably when Hsp90 inhibitors are combined with the new type of chaperone inhibitor 1,6-dimethyl3-propylpyrimido[5,4-e][1,2,4]triazine-5,7-dione (C9), which prevents Hsp90 from interacting with the cochaperone HOP (161). Very promising therapeutic option for cancer patients was reported by Ma et al (145), who targeted two chaperones Hsp90 and Hsp70 together with conventional anticancer drugs. Very similar combination of Hsp90 and Hsp70 inhibition with hyperthermia represented by ferromagnetic particles increased very effectively their antitumor effects in vitro as well as in vivo (162). For the future, it seems that the combinations of Hsp inhibitors applied with other therapies could serve as a potential solution to prevent the drug resistance and avoid the toxicity of high dose of Hsp90 inhibitors in clinical application.

\section{Acknowledgements}

This study was partly supported by the Scientific Grant Agency of the Ministry of Education of the Slovak Republic under contract no. VEGA 1/0733/12. Professional consulting service was provided by company K-TRADE spol. s r.o. (http://www. ktrade.sk/).

\section{References}

1. Neckers L: Hsp90 inhibitors as novel cancer chemotherapeutic agents. Trends Mol Med 8: S55-S61, 2002.

2. Mitsiades CS, Mitsiades NS, McMullan CJ, et al: Antimyeloma activity of heat shock protein-90 inhibition. Blood 107: 1092-1100, 2006.

3. Chiosis G, Caldas Lopes E and Solit D: Heat shock protein-90 inhibitors: a chronicle from geldanamycin to today's agents. Curr Opin Investig Drugs 7: 534-541, 2006.

4. Teng SC, Chen YY, Su YN, et al: Direct activation of HSP90A transcription by c-Myc contributes to c-Myc-induced transformation. J Biol Chem 279: 14649-14655, 2004.

5. McClellan AJ, Xia Y, Deutschbauer AM, Davis RW, Gerstein M and Frydman J: Diverse cellular functions of the Hsp90 molecular chaperone uncovered using systems approaches. Cell 131: 121-135, 2007.

6. Okamoto J, Mikami I, Tominaga Y, et al: Inhibition of Hsp90 leads to cell cycle arrest and apoptosis in human malignant pleural mesothelioma. J Thorac Oncol 3: 1089-1095, 2008.

7. Trepel J, Mollapour M, Giaccone G and Neckers L: Targeting the dynamic HSP90 complex in cancer. Nat Rev Cancer 10: 537-549, 2010.

8. Banerji U: Heat shock protein 90 as a drug target: some like it hot. Clin Cancer Res 15: 9-14, 2009.

9. Li Y, Zhang T, Schwartz SJ and Sun D: New developments in Hsp90 inhibitors as anti-cancer therapeutics: mechanisms, clinical perspective and more potential. Drug Resist Updat 12: 17-27, 2009.

10. Kamal A, Thao L, Sensintaffar J, et al: A high-affinity conformation of Hsp90 confers tumour selectivity on Hsp90 inhibitors. Nature 425: 407-410, 2003.

11. Isaacs JS, Xu W and Neckers L: Heat shock protein 90 as a molecular target for cancer therapeutics. Cancer Cell 3: 213-217, 2003.

12. Holzbeierlein JM, Windsperger A and Vielhauer G: Hsp90: a drug target? Curr Oncol Rep 12: 95-101, 2010.

13. Amolins MW and Blagg BS: Natural product inhibitors of Hsp90: potential leads for drug discovery. Mini Rev Med Chem 9: 140-152, 2009.

14. Krishna P and Gloor G: The Hsp90 family of proteins in Arabidopsis thaliana. Cell Stress Chaperones 6: 238-246, 2001.

15. Hainzl O, Lapina MC, Buchner J and Richter K: The charged linker region is an important regulator of Hsp90 function. J Biol Chem 284: 22559-22567, 2009.

16. Hawle P, Siepmann M, Harst A, Siderius M, Reusch HP and Obermann WM: The middle domain of Hsp90 acts as a discriminator between different types of client proteins. Mol Cell Biol 26: 8385-8395, 2006.

17. Lee CC, Lin TW, Ko TP and Wang AH: The hexameric structures of human heat shock protein 90. PLoS One 6: e19961, 2011. 
18. Prodromou C, Roe SM, O'Brien R, Ladbury JE, Piper PW and Pearl LH: Identification and structural characterization of the ATP/ADP-binding site in the Hsp90 molecular chaperone. Cell 90: 65-75, 1997.

19. Whitesell L, Mimnaugh EG, De Costa B, Myers CE and Neckers LM: Inhibition of heat shock protein HSP90-pp60v-src heteroprotein complex formation by benzoquinone ansamycins: essential role for stress proteins in oncogenic transformation. Proc Natl Acad Sci USA 91: 8324-8328, 1994.

20. Karkoulis PK, Stravopodis DJ, Margaritis LH and Voutsinas GE 17-Allylamino-17-demethoxygeldanamycin induces downregulation of critical Hsp90 protein clients and results in cell cycle arrest and apoptosis of human urinary bladder cancer cells. BMC Cancer 10: 481, 2010

21. Babchia N, Calipel A, Mouriaux F, Faussat AM and Mascarelli F: 17-AAG and 17-DMAG-induced inhibition of cell proliferation through B-Raf downregulation in WT B-Raf-expressing uvea melanoma cell lines. Invest Ophthalmol Vis Sci 49: 2348-2356, 2008

22. Villa R, Folini M, Porta CD, et al: Inhibition of telomerase activity by geldanamycin and 17-allylamino, 17-demethoxygeldanamycin in human melanoma cells. Carcinogenesis 24: 851-859, 2003

23. Cervantes-Gomez F, Nimmanapalli R and Gandhi V: Transcription inhibition of heat shock proteins: a strategy for combination of 17-allylamino-17-demethoxygeldanamycin and actinomycin D. Cancer Res 69: 3947-3954, 2009.

24. Messaoudi S, Peyrat JF, Brion JD and Alami M: Heat-shock protein 90 inhibitors as antitumor agents: a survey of the literature from 2005 to 2010. Expert Opin Ther Pat 21: 1501-1542, 2011.

25. Menzella HG, Tran TT, Carney JR, et al: Potent non-benzoquinone ansamycin heat shock protein 90 inhibitors from genetic engineering of Streptomyces hygroscopicus. J Med Chem 52. $1518-1521,2009$

26. Turbyville TJ, Wijeratne EM, Liu MX, et al: Search for Hsp90 inhibitors with potential anticancer activity: isolation and SAR studies of radicicol and monocillin I from two plant-associated fungi of the Sonoran desert. J Nat Prod 69: 178-184, 2006.

27. Pearl LH, Prodromou C and Workman P: The Hsp90 molecular chaperone: an open and shut case for treatment. Biochem J 410: 439-453, 2008

28. Soga S, Shiotsu Y, Akinaga S and Sharma SV: Development of radicicol analogues. Curr Cancer Drug Targets 3: 359-369, 2003

29. Chiosis G, Timaul MN, Lucas B, et al: A small molecule designed to bind to the adenine nucleotide pocket of Hsp90 causes Her2 degradation and the growth arrest and differentiation of breast cancer cells. Chem Biol 8: 289-299, 2001.

30. Kasibhatla SR, Hong K, Biamonte MA, et al: Rationally designed high-affinity 2-amino-6-halopurine heat shock protein 90 inhibitors that exhibit potent antitumor activity. J Med Chem 50 2767-2778, 2007

31. Lundgren K, Zhang H, Brekken J, et al: BIIB021, an orally available, fully synthetic small-molecule inhibitor of the heat shock protein Hsp90. Mol Cancer Ther 8: 921-929, 2009.

32. Taldone T and Chiosis G: Purine-scaffold Hsp90 inhibitors. Curr Top Med Chem 9: 1436-1446, 2009.

33. Chandarlapaty S, Sawai A, Ye Q, et al: SNX2112, a synthetic heat shock protein 90 inhibitor, has potent antitumor activity against HER kinase-dependent cancers. Clin Cancer Res 14: 240-248, 2008.

34. Jhaveri K, Taldone T, Modi S and Chiosis G: Advances in the clinical development of heat shock protein 90 (Hsp90) inhibitors in cancers. Biochim Biophys Acta 1823: 742-755, 2012.

35. Jhaveri K, Ochiana SO, Dunphy MP, et al: Heat shock protein 90 inhibitors in the treatment of cancer: current status and future directions. Expert Opin Investig Drugs 23: 611-628, 2014.

36. Raad, II, Hachem RY, Abi-Said D, et al: A prospective crossover randomized trial of novobiocin and rifampin prophylaxis for the prevention of intravascular catheter infections in cancer patients treated with interleukin-2. Cancer 82: 403-411, 1998.

37. Rappa G, Shyam K, Lorico A, Fodstad O and Sartorelli AC: Structure-activity studies of novobiocin analogs as modulators of the cytotoxicity of etoposide (VP-16). Oncol Res 12: 113-119, 2000

38. Gormley NA, Orphanides G, Meyer A, Cullis PM and Maxwell A The interaction of coumarin antibiotics with fragments of DNA gyrase B protein. Biochemistry 35: 5083-5092, 1996.

39. Marcu MG, Schulte TW and Neckers L: Novobiocin and related coumarins and depletion of heat shock protein 90-dependent signaling proteins. J Natl Cancer Inst 92: 242-248, 2000.
40. Peyrat JF, Messaoudi S, Brion JD and Alami M: Inhibitors of the heat shock protein 90: from cancer clinical trials to neurodegenerative diseases. Atlas Genet Cytogenet Oncol Haematol 15: 89-105, 2011.

41. Le Bras G, Radanyi C, Peyrat JF, et al: New novobiocin analogues as antiproliferative agents in breast cancer cells and potential inhibitors of heat shock protein 90. J Med Chem 50: 6189-6200, 2007.

42. Donnelly AC, Mays JR, Burlison JA, et al: The design, synthesis, and evaluation of coumarin ring derivatives of the novobiocin scaffold that exhibit antiproliferative activity. J Org Chem 73: 8901-8920, 2008

43. Radanyi C, Le Bras G, Marsaud V, et al: Antiproliferative and apoptotic activities of tosylcyclonovobiocic acids as potent heat shock protein 90 inhibitors in human cancer cells. Cancer Lett 274: 88-94, 2009.

44. Burlison JA and Blagg BS: Synthesis and evaluation of coumermycin A1 analogues that inhibit the Hsp90 protein folding machinery. Org Lett 8: 4855-4858, 2006.

45. Shelton SN, Shawgo ME, Matthews SB, et al: KU135, a novel novobiocin-derived C-terminal inhibitor of the $90-\mathrm{kDa}$ heat shock protein, exerts potent antiproliferative effects in human leukemic cells. Mol Pharmacol 76: 1314-1322, 2009.

46. Samadi AK, Zhang X, Mukerji R, Donnelly AC, Blagg BS and Cohen MS: A novel C-terminal HSP90 inhibitor KU135 induces apoptosis and cell cycle arrest in melanoma cells. Cancer Lett 312: 158-167, 2011

47. Eskew JD, Sadikot T, Morales P, et al: Development and characterization of a novel C-terminal inhibitor of Hsp90 in androgen dependent and independent prostate cancer cells. BMC Cancer 11: 468, 2011

48. Matthews SB, Vielhauer GA, Manthe CA, et al: Characterization of a novel novobiocin analogue as a putative $\mathrm{C}$-terminal inhibitor of heat shock protein 90 in prostate cancer cells. Prostate 70: 27-36, 2010.

49. Zhao H, Moroni E, Colombo $\mathrm{G}$ and Blagg BS: Identification of a new scaffold for hsp90 C-terminal inhibition. ACS Med Chem Lett 5: 84-88, 2013.

50. Fujiki H, Suganuma M, Okabe S, et al: Mechanistic findings of green tea as cancer preventive for humans. Proc Soc Exp Biol Med 220: 225-228, 1999.

51. Palermo CM, Westlake CA and Gasiewicz TA: Epigallocatechin gallate inhibits aryl hydrocarbon receptor gene transcription through an indirect mechanism involving binding to a $90 \mathrm{kDa}$ heat shock protein. Biochemistry 44: 5041-5052, 2005.

52. Li Y,Zhang T, Jiang Y,Lee HF, Schwartz SJ and Sun D: (-)-Epigallocatechin-3-gallate inhibits Hsp90 function by impairing Hsp90 association with cochaperones in pancreatic cancer cell line Mia Paca-2. Mol Pharm 6: 1152-1159, 2009.

53. Yin Z, Henry EC and Gasiewicz TA: (-)-Epigallocatechin-3gallate is a novel Hsp90 inhibitor. Biochemistry 48: 336-345, 2009.

54. Tran PL, Kim SA, Choi HS, Yoon JH and Ahn SG: Epigallocatechin-3-gallate suppresses the expression of HSP70 and HSP90 and exhibits anti-tumor activity in vitro and in vivo. BMC Cancer 10: 276, 2010.

55. Jacquemont C, Simon JA, D'Andrea AD and Taniguchi T: Non-specific chemical inhibition of the Fanconi anemia pathway sensitizes cancer cells to cisplatin. Mol Cancer 11: 26, 2012.

56. Peron M, Bonvini P and Rosolen A: Effect of inhibition of the ubiquitin-proteasome system and Hsp90 on growth and survival of rhabdomyosarcoma cells in vitro. BMC Cancer 12: 233, 2012

57. Kabakov AE, Kudryavtsev VA and Gabai VL: Hsp90 inhibitors as promising agents for radiotherapy. J Mol Med (Berl) 88: 241-247, 2010.

58. Vaseva AV, Yallowitz AR, Marchenko ND, Xu S and Moll UM: Blockade of Hsp90 by 17AAG antagonizes MDMX and synergizes with Nutlin to induce p53-mediated apoptosis in solid tumors. Cell Death Dis 2: e156, 2011.

59. Shintani S, Zhang T, Aslam A, Sebastian K, Yoshimura T and Hamakawa H: P53-dependent radiosensitizing effects of Hsp90 inhibitor 17-allylamino-17-demethoxygeldanamycin on human oral squamous cell carcinoma cell lines. Int J Oncol 29: 1111-1117, 2006.

60. To KK, Yu L, Liu S, Fu J and Cho CH: Constitutive AhR activation leads to concomitant ABCG2-mediated multidrug resistance in cisplatin-resistant esophageal carcinoma cells. Mol Carcinog 51: 449-464, 2012 
61. Wu X, Wanders A, Wardega P, et al: Hsp90 is expressed and represents a therapeutic target in human oesophageal cancer using the inhibitor 17-allylamino-17-demethoxygeldanamycin. Br J Cancer 100: 334-343, 2009.

62. Floris G, Debiec-Rychter M, Wozniak A, et al: The heat shock protein 90 inhibitor IPI-504 induces KIT degradation, tumor shrinkage, and cell proliferation arrest in xenograft models of gastrointestinal stromal tumors. Mol Cancer Ther 10: 1897-1908, 2011.

63. Floris G, Sciot R, Wozniak A, et al: The novel HSP90 inhibitor, IPI-493, is highly effective in human gastrostrointestinal stromal tumor xenografts carrying heterogeneous KIT mutations. Clin Cancer Res 17: 5604-5614, 2011.

64. Smyth T, Van Looy T, Curry JE, et al: The HSP90 inhibitor, AT13387, is effective against imatinib-sensitive and -resistant gastrointestinal stromal tumor models. Mol Cancer Ther 11: 1799-1808, 2012.

65. Lang SA, Moser C, Fichnter-Feigl S, et al: Targeting heat-shock protein 90 improves efficacy of rapamycin in a model of hepatocellular carcinoma in mice. Hepatology 49: 523-532, 2009.

66. Gloesenkamp C, Nitzsche B, Lim AR, et al: Heat shock protein 90 is a promising target for effective growth inhibition of gastrointestinal neuroendocrine tumors. Int J Oncol 40: 1659-1667, 2012.

67. Oikonomou E, Koc M, Sourkova V, Andera L and Pintzas A: Selective BRAFV600E inhibitor PLX4720, requires TRAIL assistance to overcome oncogenic PIK3CA resistance. PLoS One 6: e21632, 2011.

68. Moser C, Lang SA, Kainz S, et al: Blocking heat shock protein-90 inhibits the invasive properties and hepatic growth of human colon cancer cells and improves the efficacy of oxaliplatin in p53-deficient colon cancer tumors in vivo. Mol Cancer Ther 6: 2868-2878, 2007.

69. Rakitina TV, Vasilevskaya IA and O'Dwyer PJ: Inhibition of G1/S transition potentiates oxaliplatin-induced cell death in colon cancer cell lines. Biochem Pharmacol 73: 1715-1726, 2007.

70. Vasilevskaya IA, Rakitina TV and O'Dwyer PJ: Quantitative effects on c-Jun $\mathrm{N}$-terminal protein kinase signaling determine synergistic interaction of cisplatin and 17-allylamino-17-demethoxygeldanamycin in colon cancer cell lines. Mol Pharmacol 65: 235-243, 2004.

71. McNamara AV, Barclay M, Watson AJ and Jenkins JR: Hsp90 inhibitors sensitise human colon cancer cells to topoisomerase I poisons by depletion of key anti-apoptotic and cell cycle checkpoint proteins. Biochem Pharmacol 83: 355-367, 2012.

72. Tse AN, Sheikh TN, Alan H, Chou TC and Schwartz GK: 90-kDa heat shock protein inhibition abrogates the topoisomerase I poison-induced $\mathrm{G} 2 / \mathrm{M}$ checkpoint in p53-null tumor cells by depleting Chk1 and Weel. Mol Pharmacol 75: 124-133, 2009.

73. Moran DM, Gawlak G, Jayaprakash MS, Mayar S and Maki CG: Geldanamycin promotes premature mitotic entry and micronucleation in irradiated p53/p21 deficient colon carcinoma cells. Oncogene 27: 5567-5577, 2008.

74. Giessrigl B, Krieger S, Rosner M, et al: Hsp90 stabilizes Cdc25A and counteracts heat shock-mediated Cdc25A degradation and cell-cycle attenuation in pancreatic carcinoma cells. Hum Mol Genet 21: 4615-4627, 2012.

75. Huston A, Leleu X, Jia X, et al: Targeting Akt and heat shock protein 90 produces synergistic multiple myeloma cell cytotoxicity in the bone marrow microenvironment. Clin Cancer Res 14: 865-874, 2008.

76. Dote H, Cerna D, Burgan WE, Camphausen K and Tofilon PJ: ErbB3 expression predicts tumor cell radiosensitization induced by Hsp90 inhibition. Cancer Res 65: 6967-6975, 2005.

77. Li Y, Zhang T, Schwartz SJ and Sun D: Sulforaphane potentiates the efficacy of 17-allylamino 17-demethoxygeldanamycin against pancreatic cancer through enhanced abrogation of $\mathrm{Hsp} 90$ chaperone function. Nutr Cancer 63: 1151-1159, 2011.

78. De Raedt T, Walton Z, Yecies JL, et al: Exploiting cancer cell vulnerabilities to develop a combination therapy for ras-driven tumors. Cancer Cell 20: 400-413, 2011.

79. Acquaviva J, Smith DL, Sang J, et al: Targeting KRAS-mutant non-small cell lung cancer with the Hsp90 inhibitor ganetespib. Mol Cancer Ther 11: 2633-2643, 2012.

80. Proia DA, Sang J, He S, et al: Synergistic activity of the Hsp90 inhibitor ganetespib with taxanes in non-small cell lung cancer models. Invest New Drugs 30: 2201-2209, 2012.

81. Bao R, Lai CJ, Wang DG, et al: Targeting heat shock protein 90 with CUDC-305 overcomes erlotinib resistance in non-small cell lung cancer. Mol Cancer Ther 8: 3296-3306, 2009.
82. Bao R, Lai CJ, Qu H, et al: CUDC-305, a novel synthetic HSP90 inhibitor with unique pharmacologic properties for cancer therapy. Clin Cancer Res 15: 4046-4057, 2009.

83. Koizumi H, Yamada T, Takeuchi S, et al: Hsp90 inhibition overcomes HGF-triggering resistance to EGFR-TKIs in EGFRmutant lung cancer by decreasing client protein expression and angiogenesis. J Thorac Oncol 7: 1078-1085, 2012.

84. Xu L, Kikuchi E, Xu C, et al: Combined EGFR/MET or EGFR/ HSP90 inhibition is effective in the treatment of lung cancers codriven by mutant EGFR containing T790M and MET. Cancer Res 72: 3302-3311, 2012.

85. Rice JW, Veal JM, Barabasz A, et al: Targeting of multiple signaling pathways by the Hsp90 inhibitor SNX-2112 in EGFR resistance models as a single agent or in combination with erlotinib. Oncol Res 18: 229-242, 2009.

86. Tsai MS, Weng SH, Chen HJ, et al: Inhibition of p38 MAPKdependent excision repair cross-complementing 1 expression decreases the DNA repair capacity to sensitize lung cancer cells to etoposide. Mol Cancer Ther 11: 561-571, 2012.

87. Weng SH, Tseng SC, Huang YC, Chen HJ and Lin YW: Inhibition of thymidine phosphorylase expression by using an HSP90 inhibitor potentiates the cytotoxic effect of cisplatin in non-small-cell lung cancer cells. Biochem Pharmacol 84: 126-136, 2012

88. Katayama R, Khan TM, Benes C, et al: Therapeutic strategies to overcome crizotinib resistance in non-small cell lung cancers harboring the fusion oncogene EML4-ALK. Proc Natl Acad Sci USA 108: 7535-7540, 2011.

89. Normant E, Paez G, West KA, et al: The Hsp90 inhibitor IPI-504 rapidly lowers EML4-ALK levels and induces tumor regression in ALK-driven NSCLC models. Oncogene 30: 2581-2586, 2011.

90. Solit DB, Osman I, Polsky D, et al: Phase II trial of 17-allylamino-17-demethoxygeldanamycin in patients with metastatic melanoma. Clin Cancer Res 14: 8302-8307, 2008.

91. Heuckmann JM, Balke-Want H, Malchers F, et al: Differential protein stability and ALK inhibitor sensitivity of EML4-ALK fusion variants. Clin Cancer Res 18: 4682-4690, 2012.

92. Sang J, Acquaviva J, Friedland JC, et al: Targeted inhibition of the molecular chaperone Hsp90 overcomes ALK inhibitor resistance in non-small cell lung cancer. Cancer Discov 3: 430-443, 2013.

93. Koll TT, Feis SS, Wright MH, et al: HSP90 inhibitor, DMAG, synergizes with radiation of lung cancer cells by interfering with base excision and ATM-mediated DNA repair. Mol Cancer Ther 7: 1985-1992, 2008.

94. Segawa T, Fujii Y, Tanaka A, et al: Radiosensitization of human lung cancer cells by the novel purine-scaffold Hsp90 inhibitor, PU-H71. Int J Mol Med 33: 559-564, 2014.

95. Kim YM and Pyo H: Cooperative enhancement of radiosensitivity after combined treatment of 17-(allylamino)17-demethoxygeldanamycin and celecoxib in human lung and colon cancer cell lines. DNA Cell Biol 31: 15-29, 2012.

96. Sudo M, Chin TM, Mori S, et al: Inhibiting proliferation of gefitinib-resistant, non-small cell lung cancer. Cancer Chemother Pharmacol 71: 1325-1334, 2013.

97. Wainberg ZA, Anghel A, Rogers AM, et al: Inhibition of HSP90 with AUY922 induces synergy in HER2-amplified trastuzumab-resistant breast and gastric cancer. Mol Cancer Ther 12: 509-519, 2013.

98. Ono N, Yamazaki T, Nakanishi Y, et al: Preclinical antitumor activity of the novel heat shock protein 90 inhibitor CH5164840 against human epidermal growth factor receptor 2 (HER2)overexpressing cancers. Cancer Sci 103: 342-349, 2012.

99. Scaltriti M, Serra V, Normant E, et al: Antitumor activity of the Hsp90 inhibitor IPI-504 in HER2-positive trastuzumabresistant breast cancer. Mol Cancer Ther 10: 817-824, 2011.

100. Chandarlapaty S, Scaltriti M, Angelini P, et al: Inhibitors of HSP90 block p95-HER2 signaling in Trastuzumab-resistant tumors and suppress their growth. Oncogene 29: 325-334, 2010.

101. Meng Q, Chen X, Sun L, Zhao C, Sui G and Cai L: Carbamazepine promotes Her-2 protein degradation in breast cancer cells by modulating HDAC6 activity and acetylation of Hsp90. Mol Cell Biochem 348: 165-171, 2011.

102. Solit DB, Basso AD, Olshen AB, Scher HI and Rosen N: Inhibition of heat shock protein 90 function down-regulates Akt kinase and sensitizes tumors to Taxol. Cancer Res 63:2139-2144, 2003.

103. Wong $\mathrm{C}$ and Chen S: Heat shock protein 90 inhibitors: new mode of therapy to overcome endocrine resistance. Cancer Res 69: 8670-8677, 2009. 
104. Wong C, Wang X, Smith D, Reddy K and Chen S: AKT-aro and HER2-aro, models for de novo resistance to aromatase inhibitors; molecular characterization and inhibitor response studies. Breast Cancer Res Treat 134: 671-681, 2012

105. Pashtan I, Tsutsumi S, Wang S, Xu W and Neckers L: Targeting Hsp90 prevents escape of breast cancer cells from tyrosine kinase inhibition. Cell Cycle 7: 2936-2941, 2008.

106. Palacios C,Lopez-Perez AI and Lopez-Rivas A: Down-regulation of RIP expression by 17-dimethylaminoethylamino-17-demethoxygeldanamycin promotes TRAIL-induced apoptosis in breast tumor cells. Cancer Lett 287: 207-215, 2010

107. Stecklein SR, Kumaraswamy E, Behbod F, et al: BRCA1 and HSP90 cooperate in homologous and non-homologous DNA double-strand-break repair and G2/M checkpoint activation Proc Natl Acad Sci USA 109: 13650-13655, 2012.

108. Benezra R, Henke E, Ciarrocchi A, et al: Induction of complete regressions of oncogene-induced breast tumors in mice. Cold Spring Harb Symp Quant Biol 70: 375-381, 2005.

109. Smith V, Hobbs S, Court W, Eccles S, Workman P and Kelland LR: ErbB2 overexpression in an ovarian cancer cell line confers sensitivity to the HSP90 inhibitor geldanamycin. Anticancer Res 22: 1993-1999, 2002

110. Solar P,Horvath V, Kleban J, et al: Hsp90 inhibitor geldanamycin increases the sensitivity of resistant ovarian adenocarcinoma cell line A2780cis to cisplatin. Neoplasma 54: 127-130, 2007.

111. Sain N, Krishnan B, Ormerod MG, et al: Potentiation of paclitaxel activity by the HSP90 inhibitor 17-allylamino17-demethoxygeldanamycin in human ovarian carcinoma cell lines with high levels of activated AKT. Mol Cancer Ther 5: $1197-1208,2006$.

112. Mollapour M, Tsutsumi S, Donnelly AC, et al: Swe1 Wee1dependent tyrosine phosphorylation of Hsp90 regulates distinct facets of chaperone function. Mol Cell 37: 333-343, 2010.

113. Iwai A, Bourboulia D, Mollapour M, et al: Combined inhibition of Weel and Hsp90 activates intrinsic apoptosis in cancer cells. Cell Cycle 11: 3649-3655, 2012

114. Lamoureux F, Thomas C, Yin MJ, et al: Clusterin inhibition using OGX-011 synergistically enhances Hsp90 inhibitor activity by suppressing the heat shock response in castrateresistant prostate cancer. Cancer Res 71: 5838-5849, 2011.

115. O'Malley KJ, Langmann G, Ai J, Ramos-Garcia R, Vessella RL and Wang Z: Hsp90 inhibitor 17-AAG inhibits progression of LuCaP35 xenograft prostate tumors to castration resistance. Prostate 72: 1117-1123, 2012.

116. Huang HC, Yang Y, Nanda A, Koria P and Rege K: Synergistic administration of photothermal therapy and chemotherapy to cancer cells using polypeptide-based degradable plasmonic matrices. Nanomedicine (Lond) 6: 459-473, 2011.

117. Lamottke B, Kaiser M, Mieth M, et al: The novel, orally bioavailable HSP90 inhibitor NVP-HSP990 induces cell cycle arrest and apoptosis in multiple myeloma cells and acts synergistically with melphalan by increased cleavage of caspases. Eur J Haematol 88: 406-415, 2012.

118. Stuhmer T, Iskandarov K, Gao Z, et al: Preclinical activity of the novel orally bioavailable HSP90 inhibitor NVP-HSP990 against multiple myeloma cells. Anticancer Res 32: 453-462, 2012

119. Chatterjee M, Andrulis M, Stuhmer T, et al: The PI3K/Akt signaling pathway regulates the expression of Hsp70, which critically contributes to Hsp90-chaperone function and tumor cell survival in multiple myeloma. Haematologica 98: 1132-1141, 2012.

120. Kaiser M, Lamottke B, Mieth M, et al: Synergistic action of the novel HSP90 inhibitor NVP-AUY922 with histone deacetylase inhibitors, melphalan, or doxorubicin in multiple myeloma. Eur J Haematol 84: 337-344, 2010

121. Yasui H, Hideshima T, Ikeda H, et al: BIRB 796 enhances cytotoxicity triggered by bortezomib, heat shock protein (Hsp) 90 inhibitor, and dexamethasone via inhibition of p38 mitogenactivated protein kinase/Hsp27 pathway in multiple myeloma cell lines and inhibits paracrine tumour growth. Br J Haematol 136: 414-423, 2007

122. Weigert O, Lane AA, Bird L, et al: Genetic resistance to JAK2 enzymatic inhibitors is overcome by HSP90 inhibition. J Exp Med 209: 259-273, 2012

123. Fiskus W, Verstovsek S, Manshouri T, et al: Heat shock protein 90 inhibitor is synergistic with JAK2 inhibitor and overcomes resistance to JAK2-TKI in human myeloproliferative neoplasm cells. Clin Cancer Res 17: 7347-7358, 2011.
124. Fiskus W, Rao R, Fernandez P, et al: Molecular and biologic characterization and drug sensitivity of pan-histone deacetylase inhibitor-resistant acute myeloid leukemia cells. Blood 112: 2896-2905, 2008

125. Kaufmann SH, Karp JE, Litzow MR, et al: Phase I and pharmacological study of cytarabine and tanespimycin in relapsed and refractory acute leukemia. Haematologica 96: 1619-1626, 2011.

126. Best OG, Che Y, Singh N, Forsyth C, Christopherson RI and Mulligan SP: The Hsp90 inhibitor SNX-7081 synergizes with and restores sensitivity to fludarabine in chronic lymphocytic leukemia cells with lesions in the TP53 pathway: a potential treatment strategy for fludarabine refractory disease. Leuk Lymphoma 53: 1367-1375, 2012.

127. Jones DT, Addison E, North JM, et al: Geldanamycin and herbimycin A induce apoptotic killing of B chronic lymphocytic leukemia cells and augment the cells' sensitivity to cytotoxic drugs. Blood 103: 1855-1861, 2004.

128. Walsby E, Pearce L, Burnett AK, Fegan C and Pepper C: The Hsp90 inhibitor NVP-AUY922-AG inhibits NF-kappaB signaling, overcomes microenvironmental cytoprotection and is highly synergistic with fludarabine in primary CLL cells. Oncotarget 3: 525-534, 2012

129. Johnson AJ, Wagner AJ, Cheney CM, et al: Rituximab and 17-allylamino-17-demethoxygeldanamycin induce synergistic apoptosis in B-cell chronic lymphocytic leukaemia. Br J Haematol 139: 837-844, 2007.

130. Blagosklonny MV, Fojo T, Bhalla KN, et al: The Hsp90 inhibitor geldanamycin selectively sensitizes $\mathrm{Bcr}$-Abl-expressing leukemia cells to cytotoxic chemotherapy. Leukemia 15: $1537-1543,2001$

131. Peng C, Brain J, Hu Y, et al: Inhibition of heat shock protein 90 prolongs survival of mice with BCR-ABL-T315I-induced leukemia and suppresses leukemic stem cells. Blood 110: 678-685, 2007.

132. Tauchi T, Okabe S, Ashihara E, Kimura S, Maekawa T and Ohyashiki K: Combined effects of novel heat shock protein 90 inhibitor NVP-AUY922 and nilotinib in a random mutagenesis screen. Oncogene 30: 2789-2797, 2011.

133. Demidenko ZN, An WG, Lee JT, Romanova LY, McCubrey JA and Blagosklonny MV: Kinase-addiction and bi-phasic sensitivity-resistance of Bcr-Abl- and Raf-1-expressing cells to imatinib and geldanamycin. Cancer Biol Ther 4: 484-490, 2005.

134. Roue G, Perez-Galan P, Mozos A, et al: The Hsp90 inhibitor IPI-504 overcomes bortezomib resistance in mantle cell lymphoma in vitro and in vivo by down-regulation of the prosurvival ER chaperone BiP/Grp78. Blood 117: 1270-1279, 2011.

135. Dungey FA, Caldecott KW and Chalmers AJ: Enhanced radiosensitization of human glioma cells by combining inhibition of poly(ADP-ribose) polymerase with inhibition of heat shock protein 90. Mol Cancer Ther 8: 2243-2254, 2009.

136. Ohba S, Hirose Y, Yoshida K, Yazaki T and Kawase T: Inhibition of $90-\mathrm{kD}$ heat shock protein potentiates the cytotoxicity of chemotherapeutic agents in human glioma cells. J Neurosurg 112: $33-42,2010$.

137. Siegelin MD, Habel A and Gaiser T: 17-AAG sensitized malignant glioma cells to death-receptor mediated apoptosis. Neurobiol Dis 33: 243-249, 2009.

138. Sauvageot CM, Weatherbee JL, Kesari S, et al: Efficacy of the HSP90 inhibitor 17-AAG in human glioma cell lines and tumorigenic glioma stem cells. Neuro Oncol 11: 109-121, 2009.

139. Paraiso KH, Haarberg HE, Wood E, et al: The HSP90 inhibitor XL888 overcomes BRAF inhibitor resistance mediated through diverse mechanisms. Clin Cancer Res 18: 2502-2514, 2012

140. Ito A, Saito H, Mitobe K, et al: Inhibition of heat shock protein 90 sensitizes melanoma cells to thermosensitive ferromagnetic particle-mediated hyperthermia with low Curie temperature. Cancer Sci 100: 558-564, 2009.

141. Acquaviva J, Smith DL, Jimenez JP, et al: Overcoming acquired BRAF inhibitor resistance in melanoma via targeted inhibition of Hsp90 with ganetespib. Mol Cancer Ther 13: 353-363, 2014

142. Tatokoro M, Koga F, Yoshida S, et al: Potential role of Hsp90 inhibitors in overcoming cisplatin resistance of bladder cancerinitiating cells. Int J Cancer 131: 987-996, 2012.

143. Yoshida S, Koga F, Tatokoro M, et al: Low-dose Hsp90 inhibitors tumor-selectively sensitize bladder cancer cells to chemoradiotherapy. Cell Cycle 10: 4291-4299, 2011.

144. Sato A, Asano T, Ito K and Asano T: 17-Allylamino-17demethoxygeldanamycin and ritonavir inhibit renal cancer growth by inhibiting the expression of heat shock factor-1. Int J Oncol 41: 46-52, 2012. 
145. Ma L, Sato F, Sato R, et al: Dual targeting of heat shock proteins 90 and 70 promotes cell death and enhances the anticancer effect of chemotherapeutic agents in bladder cancer. Oncol Rep 31: 2482-2492, 2014.

146. Yin $X$, Zhang H, Lundgren K, Wilson L, Burrows $F$ and Shores CG: BIIB021, a novel Hsp90 inhibitor, sensitizes head and neck squamous cell carcinoma to radiotherapy. Int J Cancer 126: 1216-1225, 2010.

147. Misso G, Giuberti G, Lombardi A, et al: Pharmacological inhibition of HSP90 and ras activity as a new strategy in the treatment of HNSCC. J Cell Physiol 228: 130-141, 2013.

148. Lee CH, Hong HM, Chang YY and Chang WW: Inhibition of heat shock protein (Hsp) 27 potentiates the suppressive effect of Hsp90 inhibitors in targeting breast cancer stem-like cells. Biochimie 94: 1382-1389, 2012.

149. Newman B, Liu Y, Lee HF, Sun D and Wang Y: HSP90 inhibitor 17-AAG selectively eradicates lymphoma stem cells. Cancer Res 72: 4551-4561, 2012

150. Kelland LR, Sharp SY, Rogers PM, Myers TG and Workman P DT-Diaphorase expression and tumor cell sensitivity to 17-allylamino, 17-demethoxygeldanamycin, an inhibitor of heat shock protein 90. J Natl Cancer Inst 91: 1940-1949, 1999.

151. Gaspar N, Sharp SY, Pacey S, et al: Acquired resistance to 17-allylamino-17-demethoxygeldanamycin (17-AAG, tanespimycin) in glioblastoma cells. Cancer Res 69: 1966-1975, 2009.

152. Zhang H, Neely L, Lundgren K, et al: BIIB021, a synthetic Hsp90 inhibitor, has broad application against tumors with acquired multidrug resistance. Int J Cancer 126: 1226-1234, 2010.

153. Sharp SY, Boxall K, Rowlands M, et al: In vitro biological characterization of a novel, synthetic diaryl pyrazole resorcinol class of heat shock protein 90 inhibitors. Cancer Res 67: 2206-2216, 2007.

154. Sharp SY, Prodromou C, Boxall K, et al: Inhibition of the heat shock protein 90 molecular chaperone in vitro and in vivo by novel, synthetic, potent resorcinylic pyrazole/isoxazole amide analogues. Mol Cancer Ther 6: 1198-1211, 2007.

155. Gaspar N, Sharp SY, Eccles SA, et al: Mechanistic evaluation of the novel HSP90 inhibitor NVP-AUY922 in adult and pediatric glioblastoma. Mol Cancer Ther 9: 1219-1233, 2010.

156. McCollum AK, Teneyck CJ, Sauer BM, Toft DO and Erlichman C: Up-regulation of heat shock protein 27 induces resistance to 17-allylamino-demethoxygeldanamycin through a glutathione-mediated mechanism. Cancer Res 66: 10967-10975, 2006.

157. Sharp SY, Roe SM, Kazlauskas E, et al: Co-crystalization and in vitro biological characterization of 5-aryl-4-(5-substituted2-4-dihydroxyphenyl)-1,2,3-thiadiazole Hsp90 inhibitors. PLoS One 7: e44642, 2012.

158. McConnell JR and McAlpine SR: Heat shock proteins 27, 40, and 70 as combinational and dual therapeutic cancer targets. Bioorg Med Chem Lett 23: 1923-1928, 2013.

159. Lamoureux F, Thomas C, Yin MJ, Fazli L, Zoubeidi A and Gleave ME: Suppression of heat shock protein 27 using OGX-427 induces endoplasmic reticulum stress and potentiates heat shock protein 90 inhibitors to delay castrate-resistant prostate cancer. Eur Urol 66: 145-155, 2013.

160. Guo F, Rocha K, Bali P, et al: Abrogation of heat shock protein 70 induction as a strategy to increase antileukemia activity of heat shock protein 90 inhibitor 17-allylamino-demethoxy geldanamycin. Cancer Res 65: 10536-10544, 2005.

161. Pimienta G, Herbert KM and Regan L: A compound that inhibits the HOP-Hsp90 complex formation and has unique killing effects in breast cancer cell lines. Mol Pharm 8: 2252-2261, 2011.

162. Miyagawa T, Saito H, Minamiya Y, et al: Inhibition of Hsp90 and 70 sensitizes melanoma cells to hyperthermia using ferromagnetic particles with a low Curie temperature. Int J Clin Oncol 19: 722-730, 2014.

163. Ronnen EA, Kondagunta GV, Ishill N, et al: A phase II trial of 17-(Allylamino)-17-demethoxygeldanamycin in patients with papillary and clear cell renal cell carcinoma. Invest New Drugs 24: 543-546, 2006

164. Heath EI, Hillman DW, Vaishampayan U, et al: A phase II trial of 17-allylamino-17-demethoxygeldanamycin in patients with hormone-refractory metastatic prostate cancer. Clin Cancer Res 14: 7940-7946, 2008.

165. Sequist LV, Gettinger S, Senzer NN, et al: Activity of IPI-504, a novel heat-shock protein 90 inhibitor, in patients with molecularly defined non-small-cell lung cancer. J Clin Oncol 28: 4953-4960, 2010.
166. Oh WK, Galsky MD, Stadler WM, et al: Multicenter phase II trial of the heat shock protein 90 inhibitor, retaspimycin hydrochloride (IPI-504), in patients with castration-resistant prostate cancer. Urology 78: 626-630, 2011.

167. Richardson PG, Chanan-Khan AA, Lonial S, et al: Tanespimycin and bortezomib combination treatment in patients with relapsed or relapsed and refractory multiple myeloma: results of a phase 1/2 study. Br J Haematol 153: 729-740, 2011.

168. Modi S, Stopeck A, Linden H, et al: HSP90 inhibition is effective in breast cancer: a phase II trial of tanespimycin (17-AAG) plus trastuzumab in patients with HER2-positive metastatic breast cancer progressing on trastuzumab. Clin Cancer Res 17: 5132-5139, 2011.

169. Gartner EM, Silverman P, Simon M, et al: A phase II study of 17-allylamino-17-demethoxygeldanamycin in metastatic or locally advanced, unresectable breast cancer. Breast Cancer Res Treat 131: 933-937, 2012.

170. Pacey S, Gore M, Chao D, et al: A phase II trial of 17-allylamino, 17-demethoxygeldanamycin (17-AAG, tanespimycin) in patients with metastatic melanoma. Invest New Drugs 30: 341-349, 2012.

171. Socinski MA, Goldman J, El-Hariry I, et al: A multicenter phase II study of ganetespib monotherapy in patients with genotypically defined advanced non-small cell lung cancer. Clin Cancer Res 19: 3068-3077, 2013.

172. Modi S, Saura C, Henderson C, et al: A multicenter trial evaluating retaspimycin HCL (IPI-504) plus trastuzumab in patients with advanced or metastatic HER2-positive breast cancer. Breast Cancer Res Treat 139: 107-113, 2013.

173. Jhaveri K, Chandarlapaty S, Lake D, et al: A phase II open-label study of ganetespib, a novel heat shock protein 90 inhibitor for patients with metastatic breast cancer. Clin Breast Cancer 14: 154-160, 2014.

174. Ui T, Morishima K, Saito S, et al: The HSP90 inhibitor 17-N-allylamino-17-demethoxy geldanamycin (17-AAG) synergizes with cisplatin and induces apoptosis in cisplatinresistant esophageal squamous cell carcinoma cell lines via the Akt/XIAP pathway. Oncol Rep 31: 619-624, 2014.

175. Akimoto T, Nonaka T, Harashima K, Sakurai H, Ishikawa $\mathrm{H}$ and Mitsuhashi N: Radicicol potentiates heat-induced cell killing in a human oesophageal cancer cell line: the Hsp90 chaperone complex as a new molecular target for enhancement of thermosensitivity. Int J Radiat Biol 80: 483-492, 2004.

176. Burkitt M, Magee C, O'Connor D, Campbell F, Cornford P and Greenhalf W: Potentiation of chemotherapeutics by the Hsp90 antagonist geldanamycin requires a steady serum condition. Mol Carcinog 46: 466-475, 2007.

177. Cao X, Bloomston M, Zhang T, et al: Synergistic antipancreatic tumor effect by simultaneously targeting hypoxic cancer cells with HSP90 inhibitor and glycolysis inhibitor. Clin Cancer Res 14: 1831-1839, 2008.

178. Cao X, Jia G, Zhang T, et al: Non-invasive MRI tumor imaging and synergistic anticancer effect of HSP90 inhibitor and glycolysis inhibitor in RIP1-Tag2 transgenic pancreatic tumor model. Cancer Chemother Pharmacol 62: 985-994, 2008.

179. Zhang T, Li Y, Zhu Z, Gu M, Newman B and Sun D: MEK inhibition potentiates the activity of Hsp90 inhibitor 17-AAG against pancreatic cancer cells. Mol Pharm 7: 1576-1584, 2010.

180. Milanovic D, Firat E, Grosu AL and Niedermann G: Increased radiosensitivity and radiothermosensitivity of human pancreatic MIA PaCa-2 and U251 glioblastoma cell lines treated with the novel Hsp90 inhibitor NVP-HSP990. Radiat Oncol 8: 42, 2013.

181. Machida H,Matsumoto Y, Shirai Mand Kubota N: Geldanamycin, an inhibitor of Hsp90, sensitizes human tumour cells to radiation. Int J Radiat Biol 79: 973-980, 2003.

182. Vasilevskaya IA and O'Dwyer PJ: 17-Allylamino-17-demethoxygeldanamycin overcomes TRAIL resistance in colon cancer cell lines. Biochem Pharmacol 70: 580-589, 2005.

183. Holmes JL, Sharp SY, Hobbs S and Workman P: Silencing of HSP90 cochaperone AHA1 expression decreases client protein activation and increases cellular sensitivity to the HSP90 inhibitor 17-allylamino-17-demethoxygeldanamycin. Cancer Res 68: 1188-1197, 2008.

184. Saturno G, Valenti M, De Haven Brandon A, et al: Combining trail with PI3 kinase or HSP90 inhibitors enhances apoptosis in colorectal cancer cells via suppression of survival signaling. Oncotarget 4: 1185-1198, 2013.

185. He S, Smith DL, Sequeira M, Sang J, Bates RC and Proia DA: The HSP90 inhibitor ganetespib has chemosensitizer and radiosensitizer activity in colorectal cancer. Invest New Drugs 32: 577-586, 2014. 
186. Nguyen DM, Chen A, Mixon A and Schrump DS: Sequencedependent enhancement of paclitaxel toxicity in non-smal cell lung cancer by 17-allylamino 17-demethoxygeldanamycin. J Thorac Cardiovasc Surg 118: 908-915, 1999.

187. Wen W, Liu W, Shao Y and Chen L: VER-155008, a small molecule inhibitor of HSP70 with potent anti-cancer activity on lung cancer cell lines. Exp Biol Med (Maywood) 239: 638-645 2014 .

188. Zismanov V, Drucker L and Gottfried M: ER homeostasis and motility of NSCLC cell lines can be therapeutically targeted with combined Hsp90 and HDAC inhibitors. Pulm Pharmacol Ther 26: 388-394, 2013.

189. Zismanov V, Drucker L and Gottfried M: Combined inhibition of Hsp90 and the proteasome affects NSCLC proteostasis and attenuates cell migration. Anticancer Drugs 25: 998-1006, 2014.

190. Chen Z, Akbay E, Mikse O, et al: Co-clinical trials demonstrate superiority of crizotinib to chemotherapy in ALK-rearranged non-small cell lung cancer and predict strategies to overcome resistance. Clin Cancer Res 20: 1204-1211, 2013.

191. Miyajima N, Tsutsumi S, Sourbier C, et al: The HSP90 inhibitor ganetespib synergizes with the MET kinase inhibitor crizotinib in both crizotinib-sensitive and -resistant MET-driven tumor models. Cancer Res 73: 7022-7033, 2013

192. Smith DL, Acquaviva J, Sequeira M, et al: The HSP90 inhibitor ganetespib potentiates the antitumor activity of EGFR tyrosine kinase inhibition in mutant and wild-type non-small cell lung cancer. Target Oncol: Aug 1, 2014 (Epub ahead of print).

193. Ono N, Yamazaki T, Tsukaguchi T, et al: Enhanced antitumor activity of erlotinib in combination with the Hsp90 inhibitor CH5164840 against non-small-cell lung cancer. Cancer Sci 104: 1346-1352, 2013.

194. Jang WJ, Jung SK, Kang JS, et al: Anti-tumor activity of WK88-1, a novel geldanamycin derivative, in gefitinib-resistan NSCLCs with Met amplification. Cancer Sci: Aug 13, 2014 (Epub ahead of print). doi: 10.1111/cas.12497.

195. Ma Y, Lakshmikanthan V, Lewis RW and Kumar MV: Sensitization of TRAIL-resistant cells by inhibition of heat shock protein 90 with low-dose geldanamycin. Mol Cancer Ther 5: 170-178, 2006

196. Senju M, Sueoka N, Sato A, et al: Hsp90 inhibitors cause G2/M arrest associated with the reduction of $\mathrm{Cdc} 25 \mathrm{C}$ and $\mathrm{Cdc} 2$ in lung cancer cell lines. J Cancer Res Clin Oncol 132: 150-158, 2006

197. Russell JS, Burgan W, Oswald KA, Camphausen K and Tofilon PJ: Enhanced cell killing induced by the combination of radiation and the heat shock protein 90 inhibitor 17-allylamino-17- demethoxygeldanamycin: a multitarget approach to radiosensitization. Clin Cancer Res 9: 3749-3755, 2003.

198. Bisht KS, Bradbury CM, Mattson D, et al: Geldanamycin and 17-allylamino-17-demethoxygeldanamycin potentiate the in vitro and in vivo radiation response of cervical tumor cells via the heat shock protein 90-mediated intracellular signaling and cytotoxicity. Cancer Res 63: 8984-8995, 2003.

199. Sawai A, Chandarlapaty S, Greulich H, et al: Inhibition of Hsp90 down-regulates mutant epidermal growth factor receptor (EGFR) expression and sensitizes EGFR mutant tumors to paclitaxel. Cancer Res 68: 589-596, 2008.

200. Bai L, Xu S, Chen W, et al: Blocking NF-kappaB and Akt by Hsp90 inhibition sensitizes Smac mimetic compound 3-induced extrinsic apoptosis pathway and results in synergistic cancer cell death. Apoptosis 16: 45-54, 2011.

201. Mimnaugh EG, Xu W, Vos M, et al: Simultaneous inhibition of hsp 90 and the proteasome promotes protein ubiquitination, causes endoplasmic reticulum-derived cytosolic vacuolization, and enhances antitumor activity. Mol Cancer Ther 3: 551-566, 2004

202. Raja SM, Clubb RJ, Bhattacharyya M, et al: A combination of Trastuzumab and 17-AAG induces enhanced ubiquitinylation and lysosomal pathway-dependent ErbB2 degradation and cytotoxicity in ErbB2-overexpressing breast cancer cells. Cancer Biol Ther 7: 1630-1640, 2008.

203.Zsebik B, Citri A, Isola J, Yarden Y, Szollosi J and Vereb G: Hsp90 inhibitor 17-AAG reduces ErbB2 levels and inhibits proliferation of the trastuzumab resistant breast tumor cell line JIMT-1. Immunol Lett 104: 146-155, 2006.

204. Roforth MM and Tan C: Combination of rapamycin and 17-allylamino-17-demethoxygeldanamycin abrogates Akt activation and potentiates mTOR blockade in breast cancer cells. Anticancer Drugs 19: 681-688, 2008.
205. Munster PN, Basso A, Solit D, Norton L and Rosen N: Modulation of Hsp90 function by ansamycins sensitizes breast cancer cells to chemotherapy-induced apoptosis in an RB- and scheduledependent manner. See: E. A. Sausville, Combining cytotoxics and 17-allylamino, 17-demethoxygeldanamycin: sequence and tumor biology matters, Clin Cancer Res 7: 2155-2158, 2001. Clin Cancer Res 7: 2228-2236, 2001.

206. Ferrario A, Rucker N, Wong S, Luna M and Gomer CJ: Survivin, a member of the inhibitor of apoptosis family, is induced by photodynamic therapy and is a target for improving treatment response. Cancer Res 67: 4989-4995, 2007.

207. Hasenstein JR, Shin HC, Kasmerchak K, Buehler D, Kwon GS and Kozak KR: Antitumor activity of Triolimus: a novel multidrug-loaded micelle containing Paclitaxel, Rapamycin, and 17-AAG. Mol Cancer Ther 11: 2233-2242, 2012.

208. Solar P, Ferenc P, Koval J, et al: Photoactivated hypericin induces downregulation of HER2 gene expression. Radiat Res 175: 51-56, 2011

209. Chen SM, Guo CL, Shi JJ, et al: HSP90 inhibitor AUY922 abrogates up-regulation of RTKs by mTOR inhibitor AZD8055 and potentiates its antiproliferative activity in human breast cancer. Int J Cancer 135: 2462-2474, 2014.

210. Banerji U, Sain N, Sharp SY, et al: An in vitro and in vivo study of the combination of the heat shock protein inhibitor 17-allylamino-17-demethoxygeldanamycin and carboplatin in human ovarian cancer models. Cancer Chemother Pharmacol 62: 769-778, 2008.

211. Gray PJ Jr, Stevenson MA and Calderwood SK: Targeting Cdc37 inhibits multiple signaling pathways and induces growth arrest in prostate cancer cells. Cancer Res 67: 11942-11950, 2007.

212. Paduano F, Villa R, Pennati M, et al: Silencing of survivin gene by small interfering RNAs produces supra-additive growth suppression in combination with 17-allylamino-17-demethoxygeldanamycin in human prostate cancer cells. Mol Cancer Ther 5: 179-186, 2006.

213. Gandhi N, Wild AT, Chettiar ST, et al: Novel Hsp90 inhibitor NVP-AUY922 radiosensitizes prostate cancer cells. Cancer Biol Ther 14: 347-356, 2013.

214. Ku S, Lasorsa E, Adelaiye R, Ramakrishnan S, Ellis L and Pili R: Inhibition of hsp90 augments docetaxel therapy in castrate resistant prostate cancer. PLoS One 9: e103680, 2014.

215. Zhao M, Ma J, Zhu HY, et al: Apigenin inhibits proliferation and induces apoptosis in human multiple myeloma cells through targeting the trinity of CK2, Cdc37 and Hsp90. Mol Cancer 10: 104, 2011.

216. Shammas MA, Koley H, Bertheau RC, et al: Telomerase inhibitor GRN163L inhibits myeloma cell growth in vitro and in vivo. Leukemia 22: 1410-1418, 2008

217. Duus J, Bahar HI, Venkataraman G, et al: Analysis of expression of heat shock protein-90 (HSP90) and the effects of HSP90 inhibitor (17-AAG) in multiple myeloma. Leuk Lymphoma 47: 1369-1378, 2006.

218. Francis LK, Alsayed Y, Leleu X, et al: Combination mammalian target of rapamycin inhibitor rapamycin and HSP90 inhibitor 17-allylamino-17-demethoxygeldanamycin has synergistic activity in multiple myeloma. Clin Cancer Res 12: 6826-6835, 2006.

219. Cervantes-Gomez F, Nimmanapalli R and Gandhi V: ATP analog enhances the actions of a heat shock protein 90 inhibitor in multiple myeloma cells. J Pharmacol Exp Ther 339: 545-554, 2011

220. Sydor JR, Normant E, Pien CS, et al: Development of 17-allylamino-17-demethoxygeldanamycin hydroquinone hydrochloride (IPI-504), an anti-cancer agent directed against Hsp90. Proc Natl Acad Sci USA 103: 17408-17413, 2006.

221. Heimberger T, Andrulis M, Riedel S, et al: The heat shock transcription factor 1 as a potential new therapeutic target in multiple myeloma. Br J Haematol 160: 465-476, 2012.

222. Sugimoto K, Sasaki M, Isobe Y, et al: Hsp90-inhibitor geldanamycin abrogates G2 arrest in p53-negative leukemia cell lines through the depletion of Chk1. Oncogene 27: 3091-3101, 2008.

223. Haaland I, Opsahl JA, Berven FS, et al: Molecular mechanisms of nutlin-3 involve acetylation of p53, histones and heat shock proteins in acute myeloid leukemia. Mol Cancer 13: 116, 2014.

224. Rahmani M, Yu C, Dai Y, et al: Coadministration of the heat shock protein 90 antagonist 17-allylamino-17-demethoxygeldanamycin with suberoylanilide hydroxamic acid or sodium butyrate synergistically induces apoptosis in human leukemia cells. Cancer Res 63: 8420-8427, 2003. 
225. Jia W, Yu C, Rahmani M, et al: Synergistic antileukemic interactions between 17-AAG and UCN-01 involve interruption of RAF/MEK- and AKT-related pathways. Blood 102: 1824-1832, 2003

226. Yao Q, Nishiuchi R, Kitamura T and Kersey JH: Human leukemias with mutated FLT3 kinase are synergistically sensitive to FLT3 and Hsp90 inhibitors: the key role of the STAT5 signal transduction pathway. Leukemia 19: 1605-1612, 2005.

227. Mesa RA, Loegering D, Powell HL, et al: Heat shock protein 90 inhibition sensitizes acute myelogenous leukemia cells to cytarabine. Blood 106: 318-327, 2005.

228. George P, Bali P, Annavarapu S, et al: Combination of the histone deacetylase inhibitor LBH589 and the hsp90 inhibitor 17-AAG is highly active against human CML-BC cells and AML cells with activating mutation of FLT-3. Blood 105: 1768-1776, 2005.

229. George P, Bali P, Cohen P, et al: Cotreatment with 17-allylaminodemethoxygeldanamycin and FLT-3 kinase inhibitor PKC412 is highly effective against human acute myelogenous leukemia cells with mutant FLT-3. Cancer Res 64: 3645-3652, 2004.

230. Radujkovic A, Schad M, Topaly J, et al: Synergistic activity of imatinib and 17-AAG in imatinib-resistant CML cells overexpressing BCR-ABL - Inhibition of P-glycoprotein function by 17-AAG. Leukemia 19: 1198-1206, 2005.

231. Rao R, Fiskus W, Yang Y, et al: HDAC6 inhibition enhances 17-AAG--mediated abrogation of hsp90 chaperone function in human leukemia cells. Blood 112: 1886-1893, 2008

232. McCaig AM, Cosimo E, Leach MT and Michie AM: Dasatinib inhibits B cell receptor signalling in chronic lymphocytic leukaemia but novel combination approaches are required to overcome additional pro-survival microenvironmental signals. Br J Haematol 153: 199-211, 2011.

233. Walsby EJ, Lazenby M, Pepper CJ, Knapper S and Burnett AK: The HSP90 inhibitor NVP-AUY922-AG inhibits the PI3K and IKK signalling pathways and synergizes with cytarabine in acute myeloid leukaemia cells. Br J Haematol 161: 57-67, 2013.

234. Best OG and Mulligan SP: Heat shock protein-90 inhibitor, NVP-AUY922, is effective in combination with fludarabine against chronic lymphocytic leukemia cells cultured on CD40L-stromal layer and inhibits their activated/proliferative phenotype. Leuk Lymphoma 53: 2314-2320, 2012.

235. Robles AI, Wright MH, Gandhi B, et al: Schedule-dependent synergy between the heat shock protein 90 inhibitor 17-(dimethylaminoethylamino)-17-demethoxygeldanamycin and doxorubicin restores apoptosis to p53-mutant lymphoma cell lines. Clin Cancer Res 12: 6547-6556, 2006.

236. Rao R, Lee P, Fiskus W, et al: Co-treatment with heat shock protein 90 inhibitor 17-dimethylaminoethylamino-17-demethoxygeldanamycin (DMAG) and vorinostat: a highly active combination against human mantle cell lymphoma (MCL) cells. Cancer Biol Ther 8: 1273-1280, 2009.

237. Abramson JS, Chen W, Juszczynski P, et al: The heat shock protein 90 inhibitor IPI-504 induces apoptosis of AKT-dependent diffuse large B-cell lymphomas. Br J Haematol 144: 358-366, 2009.

238. Premkumar DR, Arnold B, Jane EP and Pollack IF: Synergistic interaction between 17-AAG and phosphatidylinositol 3-kinase inhibition in human malignant glioma cells. Mol Carcinog 45: $47-59,2006$
239. Premkumar DR, Arnold B and Pollack IF: Cooperative inhibitory effect of ZD1839 (Iressa) in combination with 17-AAG on glioma cell growth. Mol Carcinog 45: 288-301, 2006.

240. Jane EP and Pollack IF: The heat shock protein antagonist 17-AAG potentiates the activity of enzastaurin against malignant human glioma cells. Cancer Lett 268: 46-55, 2008.

241. Choi EJ, Cho BJ, Lee DJ, et al: Enhanced cytotoxic effect of radiation and temozolomide in malignant glioma cells: targeting PI3K-AKT-mTOR signaling, HSP90 and histone deacetylases. BMC Cancer 14: 17, 2014.

242. Bull EE, Dote H, Brady KJ, et al: Enhanced tumor cell radiosensitivity and abrogation of $\mathrm{G} 2$ and $\mathrm{S}$ phase arrest by the Hsp90 inhibitor 17-(dimethylaminoethylamino)-17-demethoxygeldanamycin. Clin Cancer Res 10: 8077-8084, 2004.

243. Wachsberger PR, Lawrence YR, Liu Y, et al: Hsp90 inhibition enhances PI-3 kinase inhibition and radiosensitivity in glioblastoma. J Cancer Res Clin Oncol 140: 573-582, 2014.

244.Gallerne C, Prola A and Lemaire C: Hsp90 inhibition by PU-H71 induces apoptosis through endoplasmic reticulum stress and mitochondrial pathway in cancer cells and overcomes the resistance conferred by Bcl-2. Biochim Biophys Acta 1833: 1356-1366, 2013.

245. Lin CC, Tu CF, Yen MC, et al: Inhibitor of heat-shock protein 90 enhances the antitumor effect of DNA vaccine targeting clients of heat-shock protein. Mol Ther 15: 404-410, 2007.

246. Roh JL, Kim EH, Park HB and Park JY: The Hsp90 inhibitor 17-(allylamino)-17-demethoxygeldanamycin increases cisplatin antitumor activity by inducing p53-mediated apoptosis in head and neck cancer. Cell Death Dis 4: e956, 2013

247. Bagatell R, Beliakoff J, David CL, Marron MT and Whitesell L: Hsp90 inhibitors deplete key anti-apoptotic proteins in pediatric solid tumor cells and demonstrate synergistic anticancer activity with cisplatin. Int J Cancer 113: 179-188, 2005.

248. Fu W, Sharma SS, Ma L, et al: Apoptosis of osteosarcoma cultures by the combination of the cyclin-dependent kinase inhibitor SCH727965 and a heat shock protein 90 inhibitor. Cell Death Dis 4: e566, 2013.

249. Mimnaugh EG, Xu W, Vos M, Yuan X and Neckers L: Endoplasmic reticulum vacuolization and valosin-containing protein relocalization result from simultaneous hsp90 inhibition by geldanamycin and proteasome inhibition by velcade. Mol Cancer Res 4: 667-681, 2006.

250. Martins AS, Ordonez JL, Garcia-Sanchez A, et al: A pivotal role for heat shock protein 90 in Ewing sarcoma resistance to anti-insulin-like growth factor 1 receptor treatment: in vitro and in vivo study. Cancer Res 68: 6260-6270, 2008.

251. Neznanov N, Gorbachev AV, Neznanova L, et al: Anti-malaria drug blocks proteotoxic stress response: anti-cancer implications. Cell Cycle 8: 3960-3970, 2009

252. Enomoto A, Fukasawa T, Takamatsu N, et al: The HSP90 inhibitor 17-allylamino-17-demethoxygeldanamycin modulates radiosensitivity by downregulating serine/threonine kinase 38 via Sp1 inhibition. Eur J Cancer 49: 3547-3558, 2013

253. Chinn DC, Holland WS, Yoon JM, Zwerdling T and Mack PC: Anti-tumor activity of the HSP90 inhibitor SNX-2112 in pediatric cancer cell lines. Pediatr Blood Cancer 58: 885-890, 2012. 